\begin{tabular}{|l|l|}
\hline 2. To: (Receiving Organization) & 3. From: Coriginating Organization) \\
Distribution & TWRS Projects/SST Retrieval \\
\hline 5. Proj./Prog./Dept./Div.: & 6. Design Authority/ Design Agent/Cog. \\
W-320 TWRS/TCPN \# D2991 & JW Bailey/JR Bellomy, NHC \\
\hline
\end{tabular}

8. Originator Remarks:

For approval and release.

11. Receiver Remarks: 11A. Design Baseline Document? [X] Yes [] No
4. Related EDT NO.:

$$
\mathrm{n} / \mathrm{a}
$$

7. Purchase Order No.:

$$
n / a
$$

9. Equip./Component No.:

$$
\mathrm{n} / \mathrm{a}
$$

10. Syster/Bldg./Facility: 241-C-106

12. Major Assm. Dwg. No.:

$$
n / a
$$

13. Permit/Permit Application No.: $\mathrm{n} / \mathrm{a}$

14. Required Response Date:

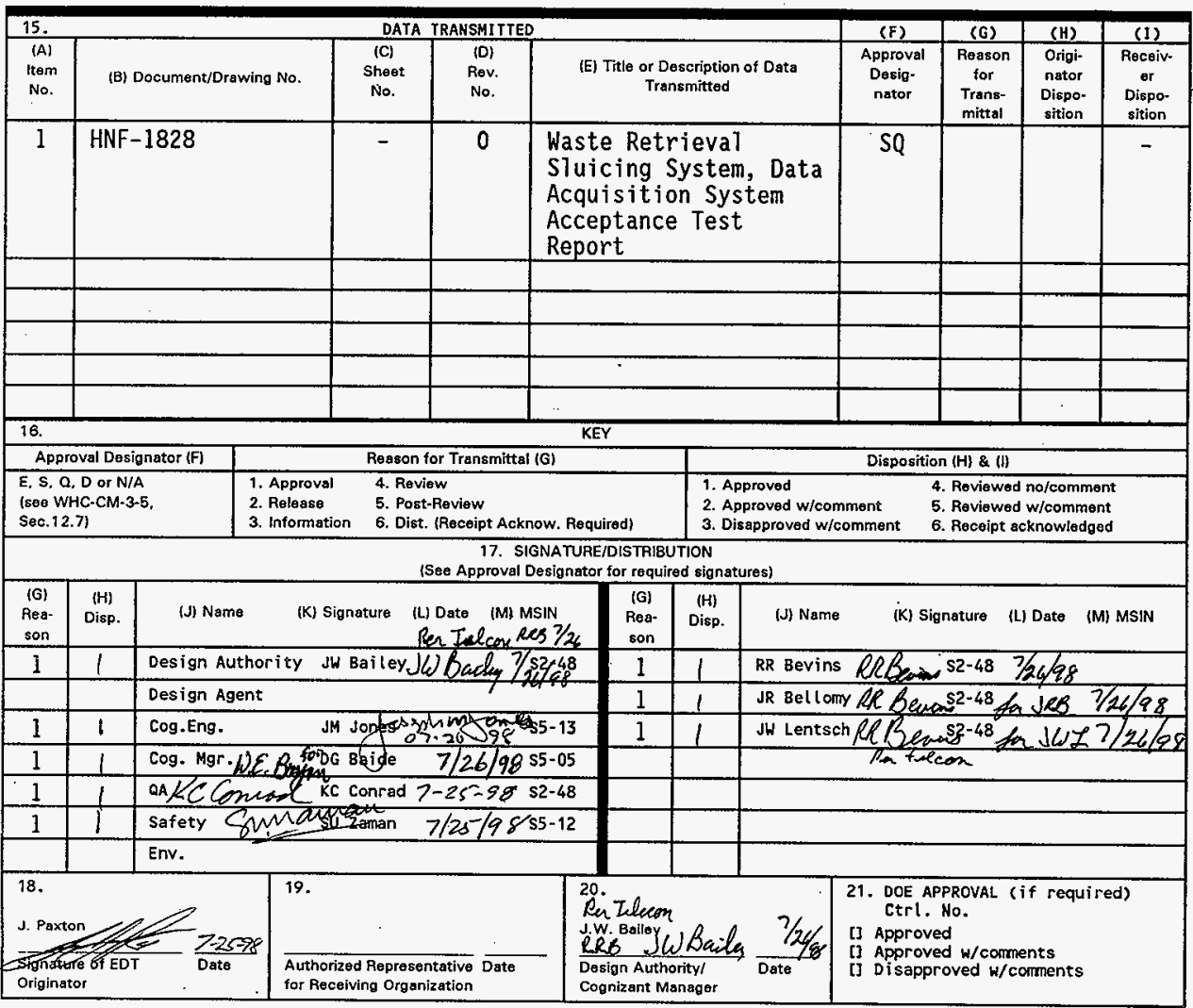




\title{
Waste Retrieval Sluicing System Data Acquisition System Acceptance Test Report
}

\author{
R. R. Bevins
}

Numatec Hanford Co., Richland, WA 99352

U.S. Department of Energy Contract DE-AC09-96RL13200

EDT/ECN: 622273

UC: 506

Org Code: $8 \mathrm{C} 452$

Charge Code: D2991/HANA0600

B\&R Code: EW3130010

Total Pages: 72

Key Words: Project W-320, Instrumentation, Data Acquisition System, Acceptance Test.

Abstract: Project W-320 Acceptance Test Report for Project W-320 Waste Retrieval Sluicing System Data Acquisition System (DAS).

TRADEMARK DISCLAIMER. Reference herein to any specific commercial product, process, or service by trade name, trademark, manufacturer, or otherwise, does not necessarily constitute or imply its endorsement, recormendation, or favoring by the United States Government or any agency thereof or its contractors or subcontractors.

Printed in the United States of America. To obtain copies of this document, contact: Document Control Services, P.O. Box 950, Mailstop H6-08, Richland WA 99352, Phone (509) 372-2420; Fax (509) 376-4989.

\section{Approved for Public Release}


$<$

ACCEPTANCE TEST PROCEDURE _HNF-1827 (W-320 DIS TEST PROCEDURE)

TEST TITLE WASTE RETRIEVAL SLUICING SYSTEM - DATA ACQUISITION SYSTEM

LOCATION AV\& CFARM

PROJECT NUMBER $\mathbf{W}-320$

TASK ORDER N-09

PROJECT TITLE W-320 Tank 241-C-106 Sluicing

Prepared By

FLUOR DANIEL NORTHWEST

Richland, Washington

For NUMATEC HANFORD COMPANY

PROCEDURE APPROVAL

FLUOR DANIEL NORTHWEST (FDNW)

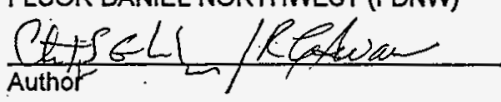

$3 / \frac{12198}{\text { Date }}$

Gayle Buran $\frac{3-1-98}{\mathrm{Date}}$

the Proudly

$\frac{3-12.98}{\text { Date }}$

Checker

TAnbulain 3.12-98
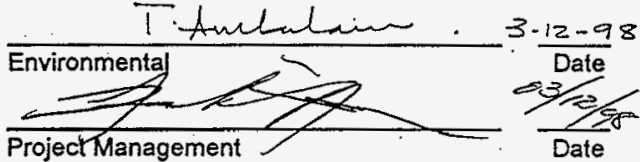

Quality Engineering

$\frac{-}{\text { Date }}$

Safety

$N / A$.

NUMATEC HANFORD COMPANY (NFC)

Projects Department

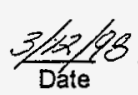

Leach Counsel

$\frac{3-12-98}{\text { Date }}$

Cinnamon

$\frac{3 / 12 / 9}{\text { Date }}{ }^{\prime} \frac{A}{\text { Operations }}$ (cods

$\frac{3 / 12 / 8 s}{\text { Date }}$

W320DAS.ATP

$-i-$

HNF-1828, Rev.0

Page $i$ 


\section{EXECUTED BY}

Test BirectoriOrganization Steve Romero $\frac{4 / 9 / 98}{\text { Date }}$ Test OperatoriOrganization

$\frac{\text { R.Toyla FOH AI }}{\text { Recorderiorganization }} \frac{4-998}{\text { Date }}$

\section{WITNESSES}

Witness/Organization

Witness/Organization

NA $\overline{\text { Date }}$
R. Jough RDit AF Tille III Inspector

$\frac{N A}{\text { Witness/Organization }}$ $\frac{4-9.98}{\text { Date }}$

Date

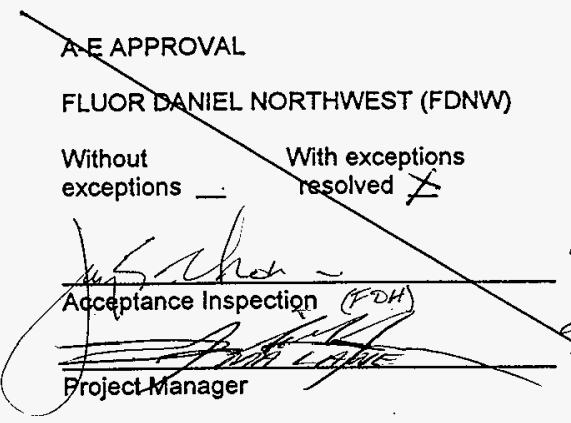

TEST APPROVAL AND ACCEPTANCE

NUMATEC HANFORD COMPANY (NHC)

Without

exceptions

With exceptions

resolved
With exceptions

outstanding -

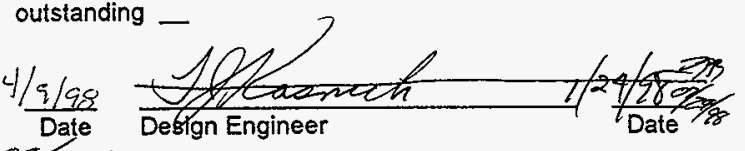

With exceptions

outstanding _-
(Title or Department)

(Title or Department)

\section{Date}

(Title or Department)

Date (Title or Department) $\overline{\text { Date }}$

Date 


\title{
WASTE RETRIEVAL SLUICING SYSTEM - DATA ACQUISITION SYSTEM ECN $\omega 320.271$ \\ $\omega 320-798$ \\ $\omega 320-812$ \\ R. R. Bevins \\ * $\omega 320-76 \%$
}

NHC, Richland, WA 99352

U.S. Department of Energy Contract DE-ACO6-96RL13200

\author{
EDT/ECN: EDT 610614 UC: 510 \\ Org Code: 80000 Charge Code: D2MEP \\ B\&R Code: EW31320010 Total.Pages: 5253 \\ xems $3 / 12 / 9 r$
}

Key Words: Project W-320, Instrumentation, Data Acquisition System, Acceptance Testing

Abstract: Project $W-320$ Acceptance Test Procedure for Project $W-320$ Waste Retrieval Sluicing System Data Acquisition System (DAS)
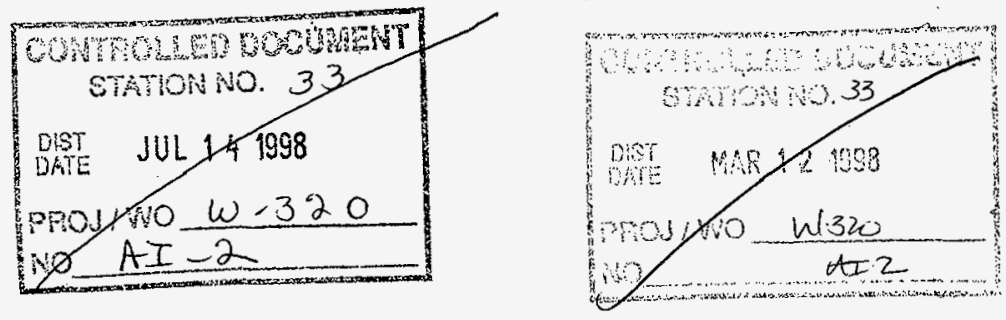

IRADEMARK DISCLAIMER. Reference herein to any specific commercial product, process, or service by trade name, trademark, manufacturer, or otherwise, does not necessarily constitute or imply its endorsement, recomendation, or favoring by the United States Government or any agency thereof or its contractors or subeontractors.

Pumped in the United States of America. To obtain copies of this document, contact: Document control Services,

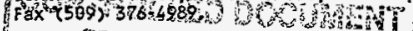
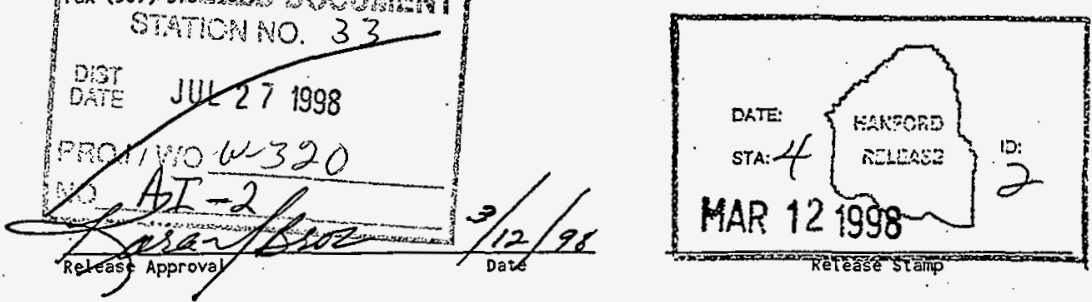

Approved for Public Release 


$$
\begin{aligned}
& \text { HNF.1827 } \\
& \text { QTP/ATP } \\
& \text { Page } i I(A)
\end{aligned}
$$

TEST EXECUTION SHEET.

TEST EXECUTION

$\frac{\text { AL Almquist FDNW } 7-1798}{\text { Installation Contractor }}$

Rus Dy

$\frac{\text { R.G. Dykeman FDH 7-17-98 }}{\text { Recorder/Organization }} \frac{\text { John Paxtod }}{\text { Test Director/Organization }} \frac{7-17-98}{\text { Date }}$

TEST WITNESS

R.G. DyKemat FDH/AI 7-17.98

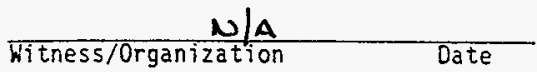

$$
\frac{\text { N/a }}{\text { Witness/Organization Date }}
$$

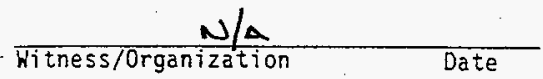

IEST ACCEPTANCE (FDNW)

SEE ATTACHED PAGE \# Ii $B$
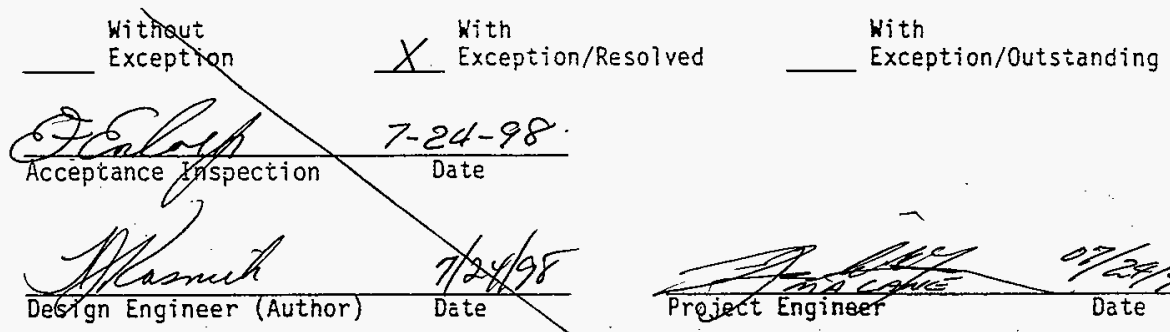

IEST APPROVAL AND ACCEPTANCE (NHC)

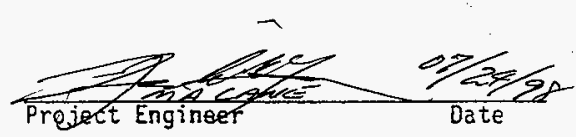

$$
\begin{aligned}
& \text { Without } \\
& \text { Exception }
\end{aligned} \text { Wxith }_{\text {Exception/Resolved }}^{\text {Wion }}
$$

RR Bewarse

Title or Department

$7 / 26 / 98$

W-320 START LP MANAGER

Date

Keith Combe $194 \quad 7-25-98$

W-320 Quante Assunanice

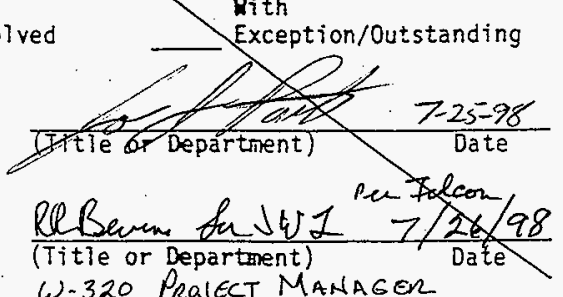

ii-A

HNF-1828, Rev.0 
EXECUTED BY

\section{to 2 LAt FDN}

Tegicicextor/Organization

P TAvion

Recorder/Organization

FDH/AI

WITNESSES

Witness/Organization

Witness/Organization

\section{A-E APPROVAL}

FLUOR DANIEL NORTHWEST (FDNW)
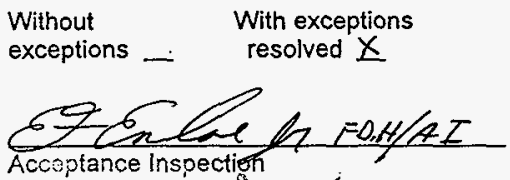

Acceptance Inspection

Projećt Ménager

With exceptions
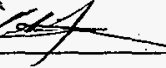
TITLESPROCEDURE APPROVAL

EXECUTIVE AND TEST APPROVAL

TABLE OF CONTENTS iii

INTRODUCTION 1

REFERENCES 2

CHANGE CONTROL 5

PREREQUISITES, EQUIPMENT/INSTRUMENTS, DEFINITIONS, GLOSSARY AND ANNUNCIATORS

\section{SOFTWARE TESTS (SECTIONS 8 - 17)}

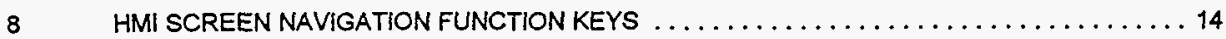

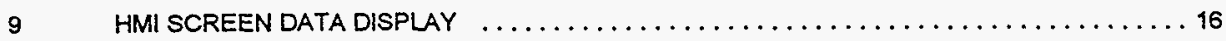

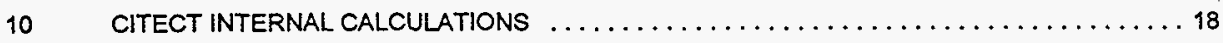

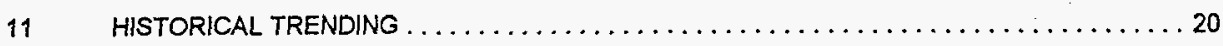

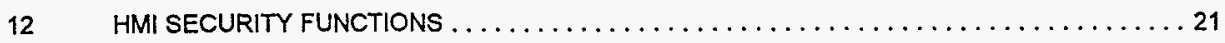

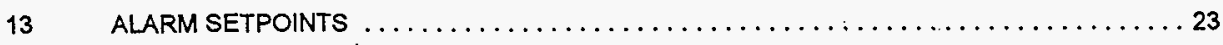

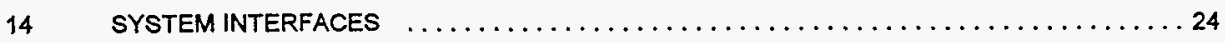

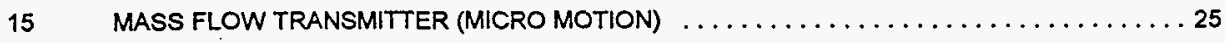

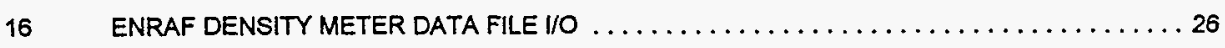

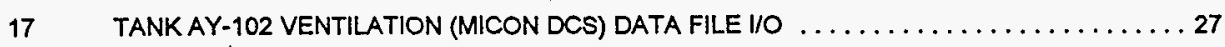

\section{FIELD TESTS (SECTIONS 19-21)}

18 AY-102 TANK TEMPERATURES (WESTRONICS MUX) ...................... 29

19 AY-FARM MIT (TYPE K THERMOCOUPLE INPUT MODULES) $\ldots \ldots \ldots \ldots \ldots \ldots \ldots 32$

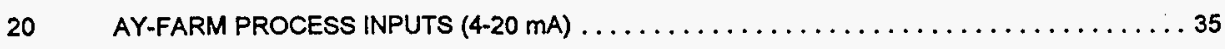

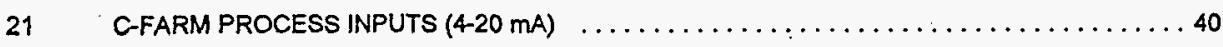




\subsection{PURPOSE}

This document describes the test procedure for the Project W-320 Tank C-106 Sluicing Data Acquisition System (W-320 DAS). The Software Test portion will test items identified in the WRSS DAS System Description (SD), HNF-2115. Traceability to HNF-2115 will be via a reference that follows in parenthesis, after the test section title.

The Field Test portion will test sensor operability, analog to digital conversion, and alarm setpoints for field instrumentation.

\subsection{SCOPE}

This test covers the display functionality, Project W-320 WRSS DAS (or DAS) networking to other systems, and overall run time performance of the WRSS DAS, including the Citect graphical interface and wireless ethernet system.

The precision of data received from analog input modules installed in the DAS Programmable Logic Controllers (PLCs) is also tested. Test cases in this document will also cover communications with remote $1 / O$ devices, such as the AY-Farm Thermocouple Multiplexer (T/C Mux), slurry mass flow and density meter, etc.

The WRSS DAS test procedure is not a calibration of sensors/transducers connected to the DAS. This procedure checks for display from sensor inputs, but assumes an accurate sensor calibration. Simulated inputs will be used to test ranges and alarm setpoints.

\subsection{OVERVIEW}

The W-320 DAS supplies data to assist thermal modeling of tanks $241-\mathrm{C}-106$ and $241-\mathrm{AY}-102$. It is designed to be a central repository for information from sources that would otherwise have to be read, recorded, and integrated manually. Thus, completion of the DAS requires communication with several different data collection devices and output to a usable PC data formats (e.g., *.CSV files for Excel, efc.). This test procedure will demonstrate that the DAS functions as required by the project requirements stated in Section 3 of the W-320 DAS System Description, HNF-2115.

\subsection{TEST CASES}

This section explains the organization of the test. Testable features of the product system include data precision, sampling rate, and data availability. The acceptance criteria are based on the system requirements defined in the WRSS DAS System Description (HNF-2115), Section 3.

The following functional areas of the DAS will be tested.

1. HMI screen navigation buttons and function keys, data display, trending, security (HNF$2115, \S 3.1 .1)$

2. HMI system interfaces (HNF-2115, § 3.1.2)

3. Communication with PLCs (tested in various sections), W-030 HVAC Unix system, Westronics SDI-310, Micro Motion RFT 9739, Enraf density profile data files (HNF-2115, $\S$ 3.1.3)

4. HMI alarm processing (HNF-2115, $\$ 3.1 .4$ ) (tested with $\mathrm{WO}$ range requirements) 
5. PLC local $/ \mathrm{O}$ functions (HNF-2115, § 3.1.3.1, § 3.1.3.7)

6. System power protection (HNF-2115, § 3.3.1)

2 REFERENCES

2.1 DOCUMENTS

ECN 639745

FDMMPT97.01

HNF-1823

HNF-2115

HNF-WM-SD-PCP-013
AY-801A Scanner Replacement

Micro Motion Mass Flow System Test (White, 1997)

Project W-320 Software Configuration Management Plan

Project W-320 WRSS DAS System Description

WRSS Process Control Plan

\subsection{DRAWINGS}

\section{ECNW $320-796$} $\equiv C N W_{220}-798$ $N 320 \rightarrow 796$ ECN $=C N W 220-798$

CNU W20 - 798 $=N$ w $200-7 a q$ un w320-798
H-2-131075, Rev $\sigma 2$ $\mathrm{H}-2-131356$, Sh 2, Rev ${ }^{\circ} \mathrm{O}$ H-2-818558, Sh 1, Rev 2 $\mathrm{H}-2-818558$, Sh 2, Rev 2 H-2-818558, Sh 3, Rev 2 H-2-818559, Sh 2 REV. 3 H-2-818560, Sh 1, Rev 3 H-2-818560, Sh 2, Rev, 23 H-2-818560, Sh 3, Rev 3 H-2-818573, Sh 1-5, Rev 1 $\mathrm{H}-2-818574$, Sh 4, Rev 0 H-2-818574, Sh 1, Rev 1 H-2-818574, Sh 5, Rev 0 H-2-818601, Sh 2, Rev $O$ H-2-818601, Sh 5, RevO H-2-818694, Sh 1, Rev 1 H-2-818695, Sh 1-5, Rev 2 H-2-818695, Sh 6, Rev 0 $\mathrm{H}-2-818698$, Sh 2, Rev 1 H-2-818699, Sh 1\&2, Rev 1 H-2-818700, Sh 1\&2, Rev 0 H-2-818700, Sh 3\&4, Rev 0 $\mathrm{H}-2-822773$, Sh 1, Rev 1
Project W-030 P\&ID

Elec Sec \& Det Recire/Clg Mdl AY \& AZ Tank Farm

Project W-320 P\&ID Legend

Project W-320 P\&ID Equipment Identification

Project W-320 P\&ID Details

Project $W-320$ P\&ID TANK 24i-C-106

Project W-320 P\&ID TANK 241-AY-102

Project $W-320$ P\&ID TANK 241-AY-102

Project W-320 P\&ID TANK 241-AY-102

Instrumentation Enclosure IE-0621 Section 7 Details Instrumentation Instrument Enclosure IE-0622 Assembly Instrumentation 241-AY-801A instr House Plan Instrumentation 241-AY-801A Instr House Connection Diagram Instrumentation Loop Diagram Tank Press \& Slurry Winch Instrumentation Loop Diagram Slurry Pres/Flo \& Bldg HVAC Electrical AY Farm Partial Site Plan Electrical AY Farm Plans \& Details Electrical AY Farm Plans \& Details Electrical AY Farm Elementary Diagrams Electrical AY Farm Conduit \& Wire Schedule Electrical AY Farm Connection Diagram Electrical AY Farm Connection Diagram Standard - C Hydrogen Monitoring System Piping \& Instr Diagram 
H-2-822774, Sh 1, Rev O

H-2-822775, Sh 5, Rev 0

H-2-822776, Sh 2, Rev 1

H-2-822777, Sh 1, Rev 1
Standard - C Hydrogen Monitoring System One Line, Elementary Diagrams

Standard - C Hydrogen Monitoring System Cabinet Assembly

Standard - C Hydrogen Monitoring System Wiring Diagram

Standard - C Hydrogen Monitoring System Loop Diagram

\subsection{SPECIFICATIONS}

W-320-C5, Rev. 0

Construction Specification Tank 241-C-106 Sluicing - C Tank

Farm

W-320-C7, Rev. 0

Construction Specification Tank 241-C-106 Sluicing - AY Tank

Farm

2.4 VENDOR INFORMATION (\#22668)

$\begin{array}{ll}\text { PO 100501-7-GliE-000 } & \text { Annulus Vent Line Flow Instrumentation } \\ \text { PO MR.21146 } & \text { Annulus Vent Line Temp Instrumentation } \\ \text { PO MR.A21780 } & \text { Primary Exhaust Humidity Instrumentation } \\ \text { PO } 78256 & \text { Slury Mass Flow Instrumentation } \\ \text { PO } 78256 & \text { Density Instrumentation }\end{array}$

3 RESPONSIBILITIES

\subsection{GENERAL}

Each company or organization participating in this test will designate personnel to assume the responsibilities and duties as defined herein for their respective roles. The designees shall become familiar with this test procedure and the systems involved to the extent that they can perform their assigned duties.

\subsection{NHC PROJECT ENGINEER}

3.2.1 Signs Execution and Test Approval page when test is complete and accepted.

3.2.2 Provides a distribution list for the approved and accepted WRSS DAS Test Procedure.

\subsection{FDNW PROJECT MANAGER}

\subsubsection{Designates a Test Director.}

3.3.2 Signs Execution and Test Approval page when test is complete and accepted.

\subsection{TEST DIRECTOR}

3.4.1 Coordinates and directs acceptance testing.

3.4.2 Coordinates testing with FDNW Utilities. 
3.4.3 Coordinates testing with FDNW Craft.

3.4.4 Before start of test, obtains all outstanding ECNs against referenced documents of Section 2, and informs the FDNW Project Manager and NHC Project Engineer of the testing schedule.

3.4.5 Notifies concemed parties (includes FDNW Project Manager, FDNW Principal Lead Engineer, and NHC Project Engineer) when a change is made/potential impact to the testing schedule.

3.4.6 Schedules and conducts a pretest kickoff meeting with test participants, when necessary.

3.4.7 Confirms that field testing and inspection of the system or portion of the system to be tested has been completed. The Test Director may also act as the Test Operator for small systems, such as the WRSS DAS.

3.4.8 Stops any test which, in his or her judgement, may cause damage to the system until the problem has been resolved.

3.4.9 After verifying there is no adverse impact, may alter the sequence in which systems or subsystems are tested.

3.4.10 If a test is to be suspended for a period of time, ensures that the system is left in a safe mode.

3.4.11 Before restarting suspended test, reverifies the test prerequisites.

3.4.12 Initiates ECNs to document required changes to the WRSS DAS Test Procedure, as needed.

3.4.13 Reviews recorded data, discrepancies, and exceptions.

3.4.14 Signs exception form when an exception has been resolved.

3.4.15 Signs Execution and Test Approval page when test has been performed.

3.4.16 Takes necessary actions to clear exceptions to the test, and signs exception form when exceptions have been resolved.

3.5 WITNESS(ES) (One witness shall be a Title llI acceptance inspector.)

3.5.1 Witnesses the tests.

3.5.2 Reviews results of testing.

3.5.3 Assists the Test Director when requested.

3.5.4 Signș Execution and Test Approval page when test has been performed.

3.5.5 Signs exception form when exception has been resolved.

\subsection{RECORDER (Provided by FDNW)}

3.6.1 Prepares a field copy from the WRSS DAS Test Procedure Master.

3.6.2 Records names of all designated personnel on field copy of test procedure before start of testing.

3.6.3 Records test instrument identification numbers and calibration expiration dates, as required. 


\subsubsection{Records test data.}

3.6.5 Record exceptions on an exception form per the Test Operator's direction. Uses additional exception forms as needed. Notifies the Test Director at time the exception is made.

3.6.6 Signs Execution and Test Approval page when test has been performed.

3.6.7 After test is finished, assigns alpha-numeric page numbers to added data sheets and exception forms. Records additional page numbers in the Table of Contents.

3.6.8 Transfers Field copy entries for each step to the Master in ink or type, signs, and dates. Transmits the completed Master to the Test Director for approval signature routing. Transmits the Field copy to Construction Document Control for inclusion in the official project file.

3.6.9 Signs exception form when exception has been resolved and transmits to Test Director.

\subsection{TEST OPERATOR}

3.7.1 Performs test under direction of the Test Director. The Test Director may also act as the Test Operator for small systems, such as the WRSS DAS.

3.7.2 Provides direction to the test recorder regarding test exceptions.

3.7.3 Provides labor, equipment, and test instruments required for performing tests which have not been designated as being provided by others.

3.7.4 Confirms that all equipment required for performing test will be available at the start of testing.

3.7.5 Signs the Execution and Test Approval page.

3.8 A-E ACCEPTANCE INSPECTION, DESIGN ENGINEER, AND PROJECT MANAGER

3.8.1 Evaluates results.

3.8.2 Signs for A-E Approval on Execution and Test Approval page.

Required changes to this ATP must be processed in accordance with company procedures. If a need for change is discovered in the course of running the test, the test shall be stopped until the ECN is approved. However, this does not prevent the running of another portion of the test unaffected by the change.

\subsection{OCCUPATIONAL SAFETY AND HEALTH}

Individuals shall carry out their assigned work in a safe manner to protect themselves and others from hazards and to prevent damage to property and environment. Facility line managers shall assure the safety of activities within their areas to prevent injury, property damage, or interruption of operation. Performance of test activities shall always include safety and health aspects. 
These tests involve working near energized equipment; all procedural requirements for working near energized equipment shall be followed, and an Energized Electrical Work Permit shall be completed.

\subsection{PERFORMANCE}

5.2.1 Conduct testing in accordance with guidelines within FDNW Practice 134.500.8354 (Performance and Recording of Acceptance Test Procedures).

5.2.2 Perform test following the steps and requirements of this procedure.

5.2.3 As each step is completed, the person witnessing the steps shall initial and date in the space provided. After each Section is completed, the witness shall initial and date in the space prokided in Section 24.

6 EXCEPTIONS

\subsection{GENERAL}

Sections 8 - 17 of this document that are test procedures for the DAS software are governed by the W-320 Software Configuration Management Plan, HNF-1823. Exceptions found in these sections fall entirely within the configuration control procedures in the WRSS DAS SCMP.

The remaining sections test PLC functionality (in conjunction with the DAS software). Exceptions to the required test results are sequentially numbered and recorded on individual exception forms. This enables case-by-case resolution and approval of each exception.

Errors/exceptions in the ATP itself shall NOT be processed as test exceptions (see Section 4, CHANGE CONTROL).

\subsection{RECORDING}

6.2.1 Number each exception sequentially as it occurs and record it on an exception form. Also, log the exception onto the exception log form.

6.2.2 Enter name and organization of the individual that identifies each exception.

6.2.3 Enter planned action to resolve each exception when such determination is made.

\subsection{RETESTIRESOLUTION}

Record the action taken to resolve each exception.

6.3.1 When action taken results in an acceptable retest, sign and date Retest Execution and Acceptance section of the exception form.

6.3.2 When action taken does not involve an acceptable retest, strike out the Retest Execution and Acceptance section of the exception form.

6.4 APPROVAL AND ACCEPTANCE

The Test Director provides final approval and acceptance of exceptions by checking one of the following on exception form: 
6.4.1 Retest Approved and Accepted: Applicable when Retest Execution and Acceptance section is completed.

6.4.2 Exception Accepted-As-Is: Requires detailed explanation.

6.4.3 Other: Requires detailed explanation.

The Test Director.signs and dates the exception form and obtains other approvals, if required.

\subsection{DISTRIBUTION}

A copy of the approved exception form is distributed to appropriate participants. The signed original is attached to the WRSS DAS Test Procedure Master Copy. 
7 PREREQUISITES, EQUIPMENT/INSTRUMENTS, DEFINITIONS, GLOSSARY AND ANNUNCIATORS

\subsection{PREREQUISITES}

The following conditions shall exist at start of testing for that portion of the system being tested.

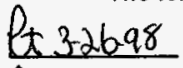

7.1.1 NHC Project Engineer has been notified prior to start of the testing.

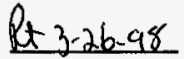

7.1.2 Electrical power is available for instruments in AY Farm; IE-0622 in AY-801A, VC-0622 Cabinet $C$ in 241-AY-51; and AZ-271 (W-030 Control Room).

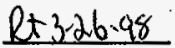

7.1 .3

Electrical power is available for instruments in CB-01, CP-01, IE-1363, and: Operator Interface Station (OIS) in MO-211; IE-1361 and IR-1361 in 241-C-S1 Process Bldg; and IE-1362 in 241-C-51.

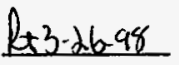

7.1.4 Systems and components have been appropriately tagged in accordance with P\&ID Drawings $\mathrm{H}-2-131075, \mathrm{H}-2-131356, \mathrm{H}-2-818559$, and $\mathrm{H}-2-818560$, and inspected for compliance with construction documents.
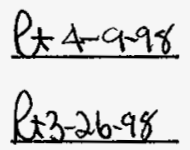

7.1 .6

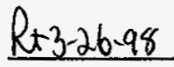

7.1.7 Wiring has been continuity tested and meggered (testing for insulation breakdown).

$2+326.98$

7.1.8 Grounding has been visually inspected and continuity tested.

$2+3-2698$

7.1.9 Voice communications are available between Tank 241-AY-102, 241-AY-801A, 241-AZ-271, and MO-211.

Re $4-998$

let3-2698

7.1.10 Calibration for instruments listed in Data Sheet 7.4 .9 is up-to-date.

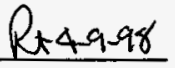

7.1.11 Test Operator possesses a set of HMI security passwords given to him by DAS Development Personnel.

7.1.12 Thermocouples associated with Westronics Mux Datalogger and listed in Appendix B of HNF-2115 have been tested for malfunction (out of range/open).

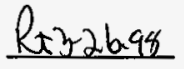

7.1 .13

DAS wireless network operational as demonstrated by DAS Development Personnel.

$1+326.98$

\subsubsection{4}

DAS field installation complete, including HLAN connection to DAS PC.

Let2-26.98

7.1 .15

D+3-26098

7.1.16 Test Operator or staff has knowiedge and skills to operate Windows NT, WRSS DAS and Citect programs.

R+3.26.9\%

7.1.17 Data log directory on Micon DCS workstation is mounted as X: on HMI PC, and data is currently being logged. 
ㄴ $3-2798$ 7.1.18 Testing of PIC-1361 and PIT-1361 is completed in accordance with W320ATP-012.

7.1 .10 ECN wa20-721

\begin{tabular}{|c|c|c|c|}
\hline \multicolumn{4}{|c|}{ DATA SHEET 7:1.9 } \\
\hline \multirow{2}{*}{ INITIALIDATE } & \multirow{2}{*}{ INSTRUMENT TAG NUMBER } & \multicolumn{2}{|c|}{ VERIFY CALIBRATION } \\
\hline & & CALNAL (DATE) & EXPIRATION DATE \\
\hline$(t+3-2) \cdot 98$ & FIT-0622 & $3-4-98$ & $3-4.01$ \\
\hline$l+3-27-94$ & TE/TIT-0620 & 3.298 & $3-2.01$ \\
\hline$R+3.22 .98$ & UE-0621/UT-0621 & $10-21.97$ & $10-20-00 ?$ \\
\hline$R+3-27.98$ & NIT-02JAY-12-1 & $2+9 \cdot 98$ & $5-19.98$ \\
\hline & $A E=0623 / A \mid T-0623$ & & \\
\hline$R+3-27-98$ & MIT (TE-06230 to TE-06251) & $2-25-98$ & $2-25-99$ \\
\hline & WSF-LIF=602A & & \\
\hline$R+3-27.98$ & FE-13616/FIT-13616 & $\Delta-12.96$ & $4-12-99$ \\
\hline $\operatorname{R+3} 27.98$ & PE-1361/PIT-1361 & 2.27 .98 & 2.27 .01 \\
\hline $2 \times 3-27-98$ & PE-1362/PIT-1362 & $3-21-96$ & $3-21-99$ \\
\hline & WSTR-SOI-3101A-AY-8OTA & & \\
\hline$k+3-27-98$ & LI-602B IN 241-AY-51 & $224-98$ & $2-24-01$ \\
\hline
\end{tabular}


The following test instruments shall be available (supplied by Test Operator).

\begin{tabular}{|c|c|c|}
\hline TYPE & $\begin{array}{l}\text { INSTRUMENT } \\
\text { NO. }\end{array}$ & $\begin{array}{l}\text { CALIBRATION } \\
\text { EXP. DATE }\end{array}$ \\
\hline $\begin{array}{l}\text { Transmitter calibrator simulator with } 4-20 \mathrm{~mA} \text { output. } \\
\text { Display must be adjustable to } \pm 0.004 \mathrm{~mA} \text { (nominal), or } \\
\text { use with } \mathrm{DMM} \text {, below. } \\
\text { u }\end{array}$ & $817 \sim 13-55-026$ & $3-30-99$ \\
\hline Digital Multimeter, with $\mathrm{mA}$ readout of \pm 0.001 units. & $817 \cdot 45-06-026$ & $3-12.99$ \\
\hline $\begin{array}{l}\text { Thermocouple simulator, Type } K \& J \text {, with display, } \\
\text { adjustable to } \pm 0.1^{\circ} \mathrm{F} \text { resolution (nominal) }\end{array}$ & $1817-13-55-013$ & $9-5-98$ \\
\hline $\begin{array}{l}\text { RTD Readout/Calibrator/Simulator: Platinum } 100 \mathrm{ohm} \\
\text { DIN, } \pm 0.1^{\circ} \mathrm{F} \text { resolution (nominal) }\end{array}$ & $817-63-02-003$ & $6-2798$ \\
\hline Variable Test Pressure Source (VTPS): 0 to. $5^{\mu} \mathrm{H}_{2} \mathrm{O}$ & $817+13$ वी 120 & $1.21+499$ \\
\hline Stop Watch ROSEMasuT MODEL 268 & N/A & N/A \\
\hline Micro Motion Model 275 HART/Communicator & $58169-A 09 E$ & $N / A$ \\
\hline ENRAF Density Meter data file available on floppy disk. & N/A & $N / A$ \\
\hline Presstre-simutator (strain gage simulator): 0-150 psig & $812-13-55-026$ & $3-30-99$ \\
\hline
\end{tabular}

\subsection{DEFINITIONS AND GLOSSARY OF TERMS}

Click: Use the mouse to point at a screen target, then press down on the button on the left side of the mouse. Compare Right-Click.

DAS: Data Acquisition System based on a PLC/PC architecture to collect field data and provide a full user interface/HMI to display, manipulate, save and print data.

DCS: Distributed Control System. A control system package combining PLC and HMI functionality, with multiple autonomous controliers and interfaces.

\section{ECN: Engineering Change Notice}

Ethernet Hub: Device used as a connection point between two or more ethernet devices. Analogous to a null modem for communication between serial devices.

HMI Software: A Human-Machine Interface software package developed by Ci Technologies, Citect, is used to create the human-machine interface portion of the DAS. The PC-based package works within the Microsoft Windows NT environment to provide graphic displays with user-friendly controls.

\section{IE: Instrument Enclosure}

I/O: Inputs and Outputs - The PLC provides the hardware interface for all field inputs and outputs which are typically divided into Discrete (On/Off) and Analog (Process Variable) types. Examples of discrete Inputs and Outputs (DI and DO) include devices such as limit switches (DI) and motor starters (DO), respectively. Process variable transmitters and variable speed drives are examples of Analog Inputs and Outputs (Al and AO), respectively. Currently there are no DOs or AOs in the DAS system. 
PC: Personal computer used with HMI software to provide the human-machine interface.

PLC: The Programmable Logic Controller is the microprocessor-based industrial controller capable of real-time control. It provides all of the discrete and process control logic required for controlling and/or monitoring the process. Once the program has been loaded into the controller module, it will execute all control/monitoring functions even if connection to the HMI computer is severed or interrupted.

Real-time: Indicates that monitoring and control signals are being processed and implemented in an acceptable time frame which is usually an imperceptible amount of time after the actual process events.

Right-Click: Use the mouse to point at a screen target, then press. down on the button on the;right side of the mouse. Compare Left-Click.

RTD: Resistance Temperature Detector

TC: Thermocouple

TCP/IP: Transport Control Protocol/internet Protocol (de facto Ethernet standard for UNIX and Microsoft Windows communications)

Tool-Tip: Phrase explaining the function of a button or other object in a HMI graphics screen that appears temporarily when the mouse pointer is moved over the object.

TWRS: Tank Waste Remediation Systems

VOM: Volt-ohmmeter

Window: Term used to describe a part or all of a complete screen display

WRSS: Waste Retrieval Sluicing System. Includes the $\mathrm{C}-106$ submersible pump, booster pump, the sluicer, the AY-102 submersible pump, booster pump, C-106 HVAC, all interconnecting piping, and instrumentation related to these items.

VTPS: Variable Test Pressure Source. 
7.4.1 WRSS DAS: The following annunciator sequence applies to all analog alarms for the WRSS DAS.

7.4.1.1 Sequence: ISA Sequence Number A (ISA S18.1)

\begin{tabular}{|l|c|c|c|}
\hline \multirow{2}{*}{ STAGE } & \multicolumn{2}{c|}{ VSUAL DISPLAY } & \multirow{2}{*}{$\begin{array}{c}\text { AUDIBLE } \\
\text { ALARM/SOUND }\end{array}$} \\
\cline { 2 - 4 } & $\begin{array}{c}\text { DISPLAY } \\
\text { STATE }\end{array}$ & COLOR & SILENT \\
\hline NORMAL & OFF & GRAY & ON/BUZZING \\
\hline UNACKNOWLEDGED - LOW/HIGH & FLASHING & AMBER & ON/PULSING CHIME \\
\hline $\begin{array}{l}\text { UNACKNOWLEDGED - } \\
\text { LOW-LOW/HIGH-HIGH }\end{array}$ & FLASHING & RED & SILENT \\
\hline ACKNOWLEDGED - LOW/HIGH & STEADY ON & AMBER & SILENT \\
\hline $\begin{array}{l}\text { ACKNOWLEDGED - } \\
\text { LOW-LOW/HIGH-HIGH }\end{array}$ & STEADY ON & RED & SILENT \\
\hline RETURN TO NORMAL & OFF & GRAY & STOR \\
\hline
\end{tabular}

7.4.2 ANN-1361, ANN-1363A, and ANN-1363B: The following annunciator sequence applies to alarms for the ANN-1361, ANN-1363, and ANN-1363B.

7.4.2.1 Sequence: ISA Sequence Number M (ISA S18.1).

\begin{tabular}{|l|c|c|}
\hline NORMAL & VSUAY SIGNAL & AUDIBEE SIGNAL \\
\hline ALERT & OFF & OFF \\
\hline ACKNOWLEDGE & FLASHING & ON \\
\hline RETURN TO NORMAL & STEADY ON & OFF \\
\hline RESET & STEADY ON & OFF \\
\hline TEST & OFF & OFF \\
\hline
\end{tabular}




\section{DAS SOFTWARE TESTS}


8 HMI SCREEN NAVIGATION AND FUNCTION KEYS (HNF-2115, § 3.1.1.1 - 2)

Tests HMI screen navigation and the function keys described in Appendix A of the DAS System Description, HNF-2115. The ACKNOWLEDGE ALARMS function key, F12, will be tested during the alarm annunciator test.

$R_{t}-32848$ 8erify applicable prerequisites from Section 7 have been completed.

FEC 3.21.78-8.2 Start WRSS DAS software.

STE $3 \times 21 \cdot 2 q_{2}$ - 8.3 Use the screen transition paths matrix checklist in Data Sheet 8.3 to verify the available transition paths to each screen.

NOTE: Test available paths from the originating screen in left-most column of Data Sheet 8.3 to each unshaded box in that row.

प्रदC $32.21 .98 \quad 8.4$ Test the following function keys:

Key Response

-F1 Displays WRSS DAS HELP

-F2 Displays TANK AY-102 STATUS

-F3 Displays TANK C-106 STATUS

F4 Displays PLC AND COMMUNICATION STATUS

F5 Displays TREND SELECTION

F6 Displays ALARM SUMMARY

HOME Refurns display to initial screen 


\begin{tabular}{|c|c|c|c|c|c|c|c|c|c|c|c|}
\hline \multicolumn{12}{|c|}{ DATA SHEET 8.3 - SCREEN TRANSITION PATHS MATRIX } \\
\hline & OVERVIEW & $\begin{array}{l}\text { AYY102 } \\
\text { STAT }\end{array}$ & C-106 STAT & $\begin{array}{c}\mathrm{PLC} / \mathrm{COMM} \\
\text { STAT }\end{array}$ & $\begin{array}{l}\text { TREND } \\
\text { SELECT } \\
\end{array}$ & $\begin{array}{c}\text { ALARM } \\
\text { SUMMARY }\end{array}$ & $\begin{array}{l}\text { AY-102 } \\
\text { TANK } \\
\text { TEMPS }\end{array}$ & $\begin{array}{c}\text { AY-102 } \\
\text { MIT }\end{array}$ & $\begin{array}{l}\text { AY-102 } \\
\text { HVAC }\end{array}$ & $\begin{array}{l}\text { AY-102 } \\
\text { DENS }\end{array}$ & $\begin{array}{l}\text { INITIAU } \\
\text { DATE }\end{array}$ \\
\hline OVERVIEW & , & 2 & $\checkmark$ & r & 12 & & & & & & $\operatorname{stc} 3.21 .28$ \\
\hline AY-102 STAT & $\checkmark$ & 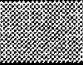 & 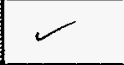 & $\checkmark$ & 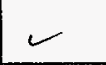 & - & 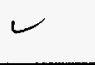 & & & ـ & $\operatorname{skc} 3.21 .98$ \\
\hline C-106 STAT & $\checkmark$ & ${ }^{2}$ & & 2 & 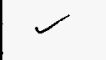 & & & & & & $\operatorname{Rze} 3 \cdot 21 \cdot 2 \mathrm{~s}_{3}$ \\
\hline $\begin{array}{l}\text { PLC/COMM } \\
\text { STAT } \\
\end{array}$ & - & r & & 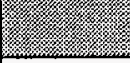 & $c$ & ح & & & & & $\operatorname{stc} 3.21 .98$ \\
\hline TREND SELECT & r & $\sigma$ & & $\checkmark$ & & 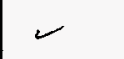 & & & & & $\operatorname{skC} 3.21 .98$ \\
\hline ALARM SUM & $\checkmark$ & $\checkmark$ & $c$ & $\Omega$ & 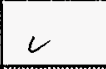 & & & & & & $\sec 3.21 .98$ \\
\hline $\begin{array}{l}\text { AY-102 TANK } \\
\text { TEMPS }\end{array}$ & & $r$ & & & & & & & & & $\mathrm{SFC} 3-21.9 \mathrm{~d}$ \\
\hline AY-102 MIT & & $\Omega$ & & & & & & & & & $\mathbb{Z} C_{3.21 .96}$ \\
\hline AY-102 HVAC & & $\widetilde{r}$ & & & & & & & & & $\operatorname{sic} 3.21 .95$ \\
\hline AY-102 DENS & & & & & & & & & & & $22 \subset 3.2 .98$ \\
\hline
\end{tabular}

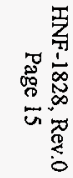


$9 \quad$ HMI SCREEN DATA DISPLAY (HNF-2115, § 3.1.1.3, 3.1.3.1, 3.1.3.7)

(1t $3-27-98$ 9.1 Verify applicable prerequisites from Section 7 have been completed.

$4 \times 3-27-98$

9.2 Log into the WRSS DAS as an Operator.

$1+3.27 .98$

9.3 Inspect WRSS DAS screens to verify that all data points listed in Data Sheet 9.3 have appropriate tags, $\mathrm{Anhit} s$, and display values within calibration range. as listed in HNF-2115, Appendix B.

Note: To change WRSS DAS screen views, click on the folder tabs at the top. Inspect pop-up screen data by clicking on grey buttons, one at a time, on each screen to display data for comparison to the HNF-2115 Appendix $B$ data point list. 
DATA SHEET 9.3 - HMI SCREEN DATA CHECKLIST

\begin{tabular}{|c|c|c|c|}
\hline \multicolumn{4}{|c|}{ DATA SHEET 9.3 - HMI SCREEN DATA CHECKLIST } \\
\hline INITIALUDATE & TAG(S) & SCREEN LOCATION/NAME & $\begin{array}{l}\text { FUNCTION } \\
\text { KEY }\end{array}$ \\
\hline Rt $3.26-96$ & T1-0520 & AY-102 STATUS & F2 \\
\hline let 326.98 & Fl-0622 & AY-102 STATUS & F2 \\
\hline$R+3-26.98$ & Al-0523 & AY-102 STATUS & F2 \\
\hline $0+3-26-98$ & A1-0621 & AY-102 STATUS & F2. \\
\hline$R+3-26-98$ & $\mathrm{DQ1}-0621 \mathrm{~A} / \mathrm{B}$ & AY-102 STATUS & F2. \\
\hline$R+3-26.98$ & DI-0621A and D1-0621B & AY-102 STATUS & $\mathrm{F} 2 \mathrm{~h}$ \\
\hline $\operatorname{lt} 3-2694$ & F1-0623 & AY-102 STATUS & $\mathrm{F} 2$. \\
\hline$p+3-2 b a y$ & T1-06230 to 06251 & AY-102 WASTE TEMPERATURES (MIT) & F2, Att-M \\
\hline$R+3.26 .94$ & 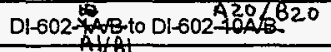 & AY-102 LEVEL AND DENSITY & F2, At-D \\
\hline $2 \times-3-26-98$ & 니-602C & AY-102 STATUS & $\mathrm{F} 2$ \\
\hline $2+3-26-98$ & $\begin{array}{l}\text { TI-01 to TI-07, TI-10 to TK-17, } \\
\text { TI-20 to TI-25 }\end{array}$ & AY-102 TANK TEMPERATURES (CONCRETE) & F2, Att-T \\
\hline$R+3-26-98$ & $T-42,44,50,55,59$ & AY-102 TANK TEMPERATURES (AIRLIFT CIRC) & F2, Att-T \\
\hline$R+3-26-98$ & $T 1-60,63,66,69$ & AY-102 TANK TEMPERATURES (DOMESPACE) & F2, Att-T \\
\hline $0+3-26-98$ & TI-61, 64, 67, 70 & $\begin{array}{l}\text { AY-102 TANK TEMPERATURES } \\
\text { (SUPERNATANT) }\end{array}$ & F2, Alt-T \\
\hline$R+4-998$ & $T-62,65,68,71,72,73,74$ & AY-102 TANK TEMPERATURES (SLUDGE) & F2, AHt-T \\
\hline $12 \times 3.26 .98$ & FI-AY2K1-2 & AY-102 HVAC & F2, Att-V \\
\hline$R+3.26-98$ & TI-AY2K48-1B & AY-102 HVAC & F2, Att-V \\
\hline $2+3-2698$ & TI-AY2EWS-1 & AY-102 HVAC & F2, Att-V \\
\hline$R+3-2698$ & TI-AY2EWR-1 & AY-102 HVAC & F2, Alt-V \\
\hline $1+3-26-94$ & FI-AY2EWR-1 & AY-102 HVAC & F2, Att-V \\
\hline$k+3-26.94$ & $\mathrm{Fl}-13616$ & C-106 STATUS & F3 \\
\hline$R+3-26-94$ & FQl-13616A & C-106 STATUS & F3 \\
\hline $12+3-26.98$ & FQl-13616B & C-106 STATUS & $F_{3}$ \\
\hline 2) $3-26-98$ & Pl-1362 & C-106 STATUS & F3 \\
\hline Rt $3-2-6.98$ & Pl-1361 & C-106 STATUS & $\overline{F 3}$ \\
\hline Dt $4 \simeq 999$ & $D 1-602 C$ & $\begin{array}{l}\text { AY- } 102 \text { AVERAGE DENSITY } \\
\text { SECTION } 9\end{array}$ & F2, ALF-D \\
\hline
\end{tabular}




\subsection{TANK C-106 BOOSTER PUMP FLOW TOTALIZER (FQI-13616AJFQI-13616B)}

$\pi \%$

Tests HMI totalizer calculation for grand (FQI-13616A) and batch (FQI-13616B). Function will not

work unless the DAS software is running continuously during waste retrieval operations.

T.3. 2898

10.1.1 Verify applicable prerequisites from Section 7 have been completed.

Q7f 321.96 10.1.2 Put the C-106 PLC inputs in simulation mode (Citect reads from disk values requires a Citect programmer).

TAC 3.21.96 10.1 .3

Restart the DAS software and log in as System Engineer.

TAP 3219t 10.1 .4

Set the booster pump discharge flow to $0 \mathrm{gpm}$, by pointing the mouse at the current value and typing "O"<enter>.

TEC $3-21.9 \% 10$

B ECN W-320-7ni

Reset the batch totalizer FQI-13616A. Note the current value of FQI-13616A, the non-resettable total volume (TO): 990 $\times 1000 \mathrm{gal}$.

MAC $3.21 .94 \quad 10.1 .6$

Set the booster pump discharge flow Fl-13616 to $300 \mathrm{gpm}$, by pointing the mouse at the current value and typing "300" <enter>. Allow the totalizer to run 5 minutes, using a digital stop watch.

$4 \mathrm{~A}_{3} \cdot 2.9 \%-10.1 .7$

Note the batch total: $1500 \times 1000$ gal. Verify that this value differs from 1500 by less than $1 \%(15 \mathrm{gal})$.

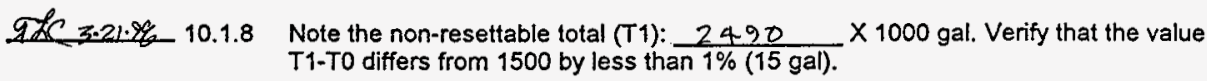

172 3.21.\% 10.1.9 Take the C-106 PLC inputs out of simulation mode (changes will not take effect until the DAS software is restarted)

170 3.21.98 10.1 .10 Restart WRSS DAS.

\subsection{WRSS SLURRY SOLIDS LOADING CALCULATION/ALARM SETPOINTS VERIFICATION}

Tests conversion of specific gravity units to percent solids, using the value for supernate density entered on the test/mairtenance page. Tests alarm set/reset points for the calculated value.

(Calculation is based on the equation in $\$ 4.1 .1$ of the the C-106 WRSS PCP, WHC-SD-NM-PCP. 013.)

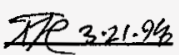

GPI $3.21 .2 \& 10.2 .2$ PIC $3+21 \cdot 9 k 10.2 .3$

PAn 3.2 .2810 .2 .4

Rt 4-9.98 ate $3 \cdot 21.9810 .2 .5$

W320DAS.ATP
Put the AY-102 PLC inputs in simulation mode (Citect reads from disk values requires a Citect programmer)

Restart the WRSS DAS software and log in as System Engineer.

Go to the test page by pressing Ctrl-Alt-T. Set the supernate density to 1.0 by using the up and down arrows.

Go to the AY-102 STATUS page. Set the slurry density $(\mathrm{g} / \mathrm{mL})$ on DI-0621A to 1.13 by pointing the mouse at the currently displayed value, then typing " $1.13^{\prime \prime}<$ enter>. Verify that the percent solids reading on DI-0621B is $20.5 \pm 0.1 \%$.

Verify that the slumy percent solids - HIGH alarm is tripped, THEN ACKNOWLFDGE

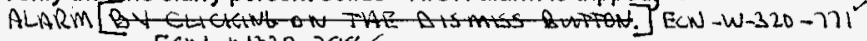
ECW $-W 320-798$ ? 

currently displayed value, then typing "1.21"<enter. Verify that the percent solids reading on Dl-0521B is $30.9 \pm 0.1 \%$.

1/2 3.21 .99210 .2 .7

Verify that the slumy percent solids - HIGH HIGH alarm is tripped. Acknowledge the alarm (F12).

Thf $3.21 .94-10.2 .8$

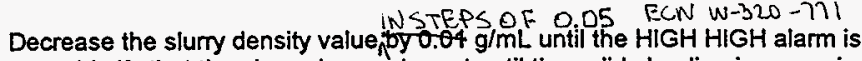
reset. Verify that the alarm does not reset until the solids loading is approximately $28 \%$.

1f( $3-21-96-10.2 .9$. Acknowledge the HIGH alarm by clicking the display symbol. Decrease the slurry density value by $0.01 \mathrm{~g} / \mathrm{mL}$ until the HIGH alarm is reset. Verify that the alar:m does not reset until the solids loading is approximately $18 \%$.

IKe $3-21.95$ 10.2.10 Take the AY-801A PLC inputs out of simulation mode and restart WRSS DAS.

END OF SECTION 10 
Tests adjustable parameters on the DAS TREND SELECTION screen.

$R+3-28.98$ Verify applicable prerequisites from Section 7 have been completed.

T.Xe $\quad 3-21.9 \& 11.2 \quad$ Log in as System Engineer.

AR $3-21.98$ Go to the TREND SELECTION screen (F5). Right-click on one of the 10 configuration buttons on the left side of the screen. A form will be displayed with text input fields and drop-down menus.

11.4 Verify that the form displayed in Step 11.3 is functional as follows:

T12 3.21.9\% 11.4.1 Select 5 trend pens: Al-0621, Al-0623, TI-06230; F1-0622, PI-1361. Select a plot span of 10 minutes.

$1703-21.78$. 11.4 .2

Enter a minimum and maximum value for each pen corresponding to the instrument ranges shown in Appendix B of the WRSS DAS System Description, HNF-2115.

STP 3.2 .98 11.4.3 Enter a title for the plot.

1.21.98 11.4.4 Save the data.

Gte $3-21.98$ 11.4.5 The window will close.

11.5 View the stored configuration and restore the default values as follows:

Re $3.21 .9 \% 11.5 .1$ Right-click the button from Step 11.3.

AZC $3-21.98$ 11.5.2 Verify the data is as entered in Step 11.4.

Iff $3-21.9 \%$ 11.5.3 Click DEFAULTS to recall the default values. The old configuration will appear on the form.

THe $3-21.78$ 11.5.4 Click SAVE to restore the default values to the database.

Ife 3.21 .98 Left-click the button configured in Step 11.4. The trend configuration will be transferred to the plot.

$523-21.98-11.7$

ECN $w-320-771$ C: TREND.CSV Click the SAVE TREND DATA TO DISK (an icon). Name the file G.TREND.XtS: Note the following:

\begin{tabular}{|c|c|c|}
\hline End Time: & $1: 49$ & 3.21 .98 \\
\hline Trend Span: & $10 \mathrm{mins}$ & Pen in Focus: PI 1321 \\
\hline
\end{tabular}

IRT $3.21 \cdot 98 \quad 11.8$ Click the COPY TREND DATA TO CLIPBOARD (icon).

QREC $3-21-98$ Go to the TEST page (Ctri-Alt-T). Click OPEN NT EXPLORER. Open a view of C.: and open C:ITREND.XLS. Verify the end time and date for the data, the tag name of the pen in focus, and the trend span recorded previously.

The 3.21 .9811 .10

Select an empty column of the worksheet. Paste (the data from Step 11.8.) Verify the pasted data is approximately the same as the data that was saved to disk. Close Excel without saving changes.

END OF SECTION 11 
Tests user (viewing, Operator-level, shift supervisor-level and System Engineer-levei) access to privileged portions of the DAS. NOTE: Access to alarm acknowledgment will be tested with the PLC LOCAL I/O procedure.

$(x-27.48 \quad 12.1$ Verify applicable prerequisites from Section 7 have been completed.

12.2 NOT LOGGED IN (VIEW ONLY)

k+3-27-98 12.2.1 Log out of the DAS if logged in.

Ri3-27-98 12.2.2 Verify the absence of minimize/close buttons for the DAS OVERVIEW screen. Click on the SHUT DOWN DAS button to verify that it is INACTIVE.

ALT-SPACE

Rt 4.9 .98 12.2.3

ECN $w-320-771 \%$

ECN w-320-798

Rt $3-27-98$ 12.2.4

Verify that none of the following key combinations (Alt-Tab Alt-Esc, Etrt-Alt-Det) reboots the HMI PC or swilehes the active-application to any other Windows

function or program. ALLOWS THE USER TO CHANGF THE ACTIVE APDLICATION OR YIEW OFHER WINDOWS NT FUNCTONS. VER Y W THAT PRESSING GTRLALTGO to the ALARMS screen (FE). Right-click one of the alam annunciator windows.

Verify that the alarm setpoint form does NOT appear.

Rt 3.27 .98 12.2.5 Click one of the alarm annunciator windows. An alarm display window appears. Verify that the ALARM CONFIGURATION bution is INACTIVE.

$2+3-27.94,12.2 .6$ Go to the TREND SELECTION screen (F5). Verify that there is no response to left- and right-clicking the 10 plot configuration buttons and DEFINE BUTTON.

\subsection{OPERATOR-LEVEL SECURITY}

$l(3-2)-9 \$ 19$ 12.3.1 Go to the OVERVIEW screen (HOME key). Log in as Operator.

$2+3-27.98$

$R+4-9.98$

ECN $w-320-771$

gew

$R+3-27-98$

$2+3-27-98$

12.3.5

$R+3-2) \cdot 98$

12.3.6
Verify the absence of minimize/close buttons for the DAS OVERVIEW screen. Click on the SHUT DOWN DAS button to verify that it is INACTIVE.

ALT-SPACE

Verify that none of the following key combinations (Alt-Tab,Alt-Esc, EtA-AH-Bet) reboots the HMHPC or switches the active application-to ant

ftnotion or orogram ALLOWS THE USER TO CHTHNG THE ACTUE ASBLICANOW OR

VIEW O WHER WWNDOWS NT FUNCTIONS. VERIFY THAT PRESSIWL CTRL-ALT-DEL DORS

NOT ALLOW THE USER TO RUN TASK MANALER OR-SAUOW OHE AE:-

Click one of the alarm annunciator windows. An alarm display window appears.

Verify that the ALARM CONFIGURATION button is ACTIVE.

- Go TO THE ALARmS SCREBN CFG) ECN W-320-7)

Go to the TREND SELECTION screen (F5). Click DEFINE BUTTON. Verify that the MAKE DEFAULT button is ABSENT from the form that appears.

Right- and left-click the plot configuration buttons to verify that trends may be configured and activated.

12.4 SHIFT SUPERVISOR-LEVEL SECURITY

R 3 -27.98 12.4.1 Go to the OVERVIEW screen (HOME key). Log in as SUPERVISOR.

R+ 3.2798 12.4.2 Verify the ABSENCE of minimize/close buttons for the DAS OVERVIEW screen.

Click on the SHUT DOWN DAS button to verify that it is INACTIVE. 
Verify that none of the following key combinations (Alt-Tab,Ait-Esc, Eirt-Alt-Bet) reboots the HAHPC or switches-the active applieationto-any other Windows

funetion or program ALLWUS THE USER TOCAANGE THE ACNVE APALCATIOW OR VIEW THER WINDOWS NT FUNCTIDNS. VBRIFY THAT PRESSING GTRL-ALT-DEL DOES NOT RLOW THE USER TO RUN TASK MHNAGRR OR-SH DOW FCN W $320-798$

DELETED PER 12.4.4 Openthe annunciator window fom Step 12.23 . Verify that the ehange was saved.

ECN - W-320-77) Restore the default values by elieking DEFAULTS. Verify that the defautis were restered.

A $3-27.98$ 12.4.5 Click one of the alarm annunciator windows. An alarm display window appears.

Verify that the ALARM CONFIGURATION button is ACTIVE.

(253-279 98 12.4.6 Go to the TREND SELECTION screen (F5). Click DEFINE BUTTON. Verify that the MAKE DEFAULT button is ABSENT on the form that appears.

$1+3.27 .98,12.4 .7$ Right- and left-click the plot configuration buttons to verify that trends may be configured and activated.

\subsection{SYSTEM ENGINEER-LEVEL SECURITY (FULL ACCESS)}

Rr $3-27.98$ 12.5.1 Go to the OVERVIEW screen (HOME key). Log in as System Engineer.

$2+3-27.98 .12 .5 .2$

Verify the ABSENCE of minimize/close buttons for the DAS OVERVIEW screen. Click on the SHUT DOWN DAS button to verify it is ACTIVE.

\section{$1+4.9 .93 \quad 12.5 .3$}

FCN $w-320-771 \%$ ECN $-W 320-796$.

DELETRD PER 42.5 .4

ECN WI20-ITा.

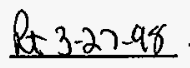

$k+3-27.98$

Rt 3.27 .98

RT $3-2798$

R+ 3-27-98

$2+3-27-98$

$\ln 3-2798$

1) 3-2)96
12.5.10

12.5.12

$$
\text { ALT-SPACE }
$$

Verify that none of the following key combinations (Alt-TabnAlt-Esc, Ct+Alt-Det) reboots the-HMI PC or switches the-aetive-applieation to any other windows

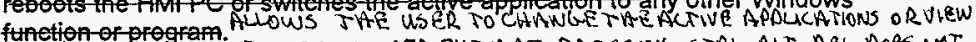
OTHER WINLOWS NTRUNCTIONS VERIFU THAT PRESSING CTRL-ALT-DEL DOES NOT

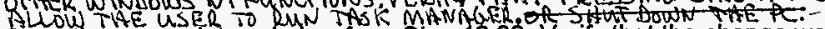

Openthe-anntunctator whow fromstep 12.23. Vertithat the-change was-saved.

Restore the defautl values by clieking DEFAULTS. Verify that the defaults were restored.

Click one of the alarm annunciator windows. An alarm display window appears. Verify that the ALARM CONFIGURATION button is ACTIVE.

Go TO. THE ALARMS SCREEN (FG) ECNW-320-i71-

Go to the TREND SELECTION screen (F5). Click DEFINE BUTTON. Verify that the MAKE DEFAULT button is PRESENT on the form that appears.

Right- and left-click the plot configuration buttons to verify that trends may be configured and activated.

Go to the OVERVIEW screen (HOME key).

Click ADD/EDIT USERS. Verify that new users MECoR be privileges may be-changed with fom appears: CuRRENT USBRS MAY BR

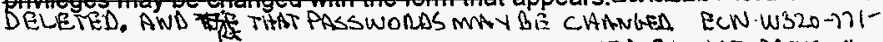

Press-CTRE-ALT-M to display the flat-sereen mentr VERIFA THAT PRESSING CTRL-ALT-M DLPLAYS TAS RLAT SCRERN MENU. ELN Wa320-771-

Press-GTRL-ALT-T to display the-test page. VERIFA THAT PR.SSING CTRL-ALT-T DISPLAYS THE JEST PAGR. ECN W-320-371-

Log out of the DAS. 
Tests the alarm setpoint change and enable/disable functions.

NOTE: LIT-602A has been selected as an example. All other alarms operate on the same program code and do not need to be tested.

$R_{+} 3.25^{-966} 13.1$ Verify applicable prerequisites from Section 7 have been completed.

ACC $3-21.2 E_{13.2}$ Log in as System Engineer.

FLC 3-21-98 13.3 Put AY-801A PLC in simulation mode (Requires Citect programmer). Restart WRSS DAS software. Log in as Shift Supervisor.

AXC 3-21.9\& 13.4 Go to the ALARMS screen (F6). Right-click the alarm annunciator window for LI-602C. A form should be displayed showing the alarm tag and current setpoints.

Iff $3 \cdot 21.98-13.5$ Record the current high alarm setpoint: $220 \cdot 0^{\prime}$ inches.

4 IC-3.21.92 13.6 Click the DISABLE checkbox for LI-602C. Save the alarm configuration form.

TRC 3-21.98_13.7 Go to the AY-102 STATUS page. Increase value of LI-602C above the HIGH alarm setpoint recorded in Step 13.5 by pointing the mouse at the currently displayed value, and typing in (integar $=H \mathrm{sp}+5$ ), and press <enter>. Go to the ALARM SUMMARY page and verify that no alarm has tripped.

IXC $3.21 .94 \quad 13.8$ Go back to the AY-102 STATUS page and decrease the value of LI-602C to 120 inches.

F_C 3-21.92 13.9 Go to the ALARMS screen (F6). Right-click the alarm annunciator window for LI-602C. Re-enable the disabled alarm.

$\operatorname{Ta} 3-21.98-13.10$

Change the high alarm seipoint on the form to 150 inches, and click the SAVE button. REVERIF-1 DATA WAS SAVED. ECN W-320-771-

T2t $3-21.9 \& 13.11$

Go to the AY-102 Status screen and enter a value of 160 . Verify that the alarm trips. Acknowledge the alarm.

茫 $3.21 .96-13.12$

Recall the form to eheck if the new-data has been-saved. Click DEFAULTS and verify that original data appears in the form, AS TAAT RECOKD RD oN STEP 13.5 ELN W320-171-

GKC 3.21.9\% 13.13 Click SAVE to close the fOTm. REVERIFY DATA WAS SAVEO RUN-W320-171$973.21 .9613 .14 \mathrm{Log}$ in as System Engineer.

YXX e 3.21 .9813 .15 Take AY-801A PLC out of simulation mode. Restart WRSS DAS.

\section{END OF SECTION 13}


Tests reporting frequency, data file turnover, and HLAN access for WRSS DAS periodic reports.

$\frac{R+4-98}{R+4-94}$

14.2

RA4-198

Re $4-1-96$

14.4

ECW W-320-7า1

R+ $4-1-99$

14.5

$2+4-1-98$

14.6

$2+4-195$

R+4-1.94

14.7

14.8

R+ A-198

14.9

DELETEO PER ECN $w-320-7) 1$

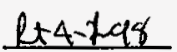
R+4-2.95

$R+4-2.94$

$R+A-2=98$
Verify applicable prerequisites from Section 7 have been completed.

SHUT DOWN THE DAS CTHIS DEQURRES THAT WINDOWS NT

Log in as System Engineer. Go to tho TESI pago and open the Hindows

Explorer. Delete the files C:ICitectiDatal*.CSV (all DAS history files). IS NOT SET UP Wint CITECT 32 AS TAE SAELL) ECN W-320-711.

3:45 ECN W320-771-

Use the Date/Time control panel to change the system time to $4.55 \mathrm{AM}$.

Restart the WRSS DAS and log in as System Engineer. Allow the DAS to acquire data for a minimum of one hour and tet minutes, control-panetto- tonge-system to- $4: 55$ AM on the following day.

tetthe software run foranotherten minutes, then go to the TEST page and open the Windows NT Explorer. ECN w-320-77!

Open a file list of C:ICitectlData. Copy the previous day's reportfftes (test to c:lCitect. RECENTLY CLOSED AND CURRENT REAORT FILES C ${ }^{*}$. CSVI ECWW320-771

Using the Windows NT Explorer, open the files in Microsoft Excel.

NOT CONTAINING A DETE CODE \& CSV NOT INCLUDING AFCSV

Verify that each file stats-with a header-row listing the datapoints-recorded in the

-file.-Verify that the each header's-tag list is identieat to the eorresponding report definition flle's tag list. See-HAF-2145, Append $x$, for a tist of report deffintion fleS.ORENRAF. CSVJ CONTAINSA HERDRR ROW LISTING THEDATA POINTS RECORDED WN HIW FRLE RCN W-320-7) FI.

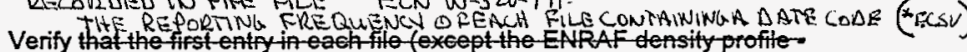

ENRAF.ESW was recorded within one-trend period of 5:00 AN4 (see-1AF-2145,

WRSS-DAS-SYstem Describtion. Appendix B) BY CHEUKING MHE TIMESTMMP ON2.

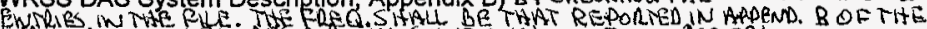

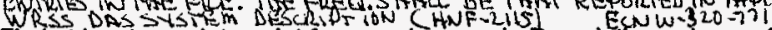

14.10. Find at least one data point from eaengroup in Deseription column of HNF-2445, Appendix $B$, and verify the reperting frequengy in the histery flles:

\subsection{Close Microsoft Excel and the Explorer. Log out of the DAS}

14.12 On a remote workstation (in MO-294, for example); open the Map Network Drive dialog in the Windows Explorer (or File Manager). Map the next available drive letter to "IWWC62613ICTDATA".

14.13 Open a listing of the files in the network volume, and copy the files ".CSV to the local hard drive.

14.14 Open one of the files in Microsoft Excel, and verify that it contains WRSS DAS data. 
The following tests functionality of the mass flow transmitter UT-0621 by verifying the communication to the PLC/DAS functions for the W-320 slurry line.

NOTE: The Mass Flow Element and Transmitter were tested by PNNL, Ref. FDMMPT97.01.

L $+4-2.98$ R+ 4.2 .98

$\operatorname{Ri} 4-9-98$

ECN-W $320-798$

$\operatorname{R+4}-2-98$
15.1 Verify applicable prerequisites from Section 7 have been completed.

15.2 With the DAS software running, open the AY-102 STATUS screen. Verify that DI-0621A, FI-0623, DQI-0621A (GRAND TOTAL), and DQI-0621B (BATCH TOTAL) are within the calibration range listed in HNF-2115, Appendix $B$.

OR ROSEMOUNT MODiEl 268 At Tank 241-AY-102 Pump Pit 02A, connect the Micro Motion Model 275 HART, Communicator to the Micro Motion RFT9739 field mount transmitter, UT-0621, terminals $17(+)$ and $18(-)$. Verify that the Modet 275 field readings for MASS FLOW, DENSITY, and TOTAL MASS are the same as those displayed on the WRSS DAS.
HART

15.4 Disconnect the HART Communicator.

END OF SECTION 15 
Tests processing of density meter data files generated by the meter control program.

NOTE: Operating accuracy for this equipment was established in maintenance procedure 6-TF-125. File names generated by the density meter control program are numbered sequentially: The most recent file will have the highest number.

St 3-27.98

Rr3.27.98

Bt 3-27.94

$R+3.27-98$

$2+3-27-48$

16.1

16.2

16.3

16.4

ECN $W-320-771-$

$k+3-27-98$

16.6

Le 3-27-98

16.7

ECN w320-711-

$2+3-27.98$

16.8 Log out of the DAS. last line of the file.

$\begin{aligned} & \text { SuRPACE } \\ & \text { DI-602A } \\ & B S\end{aligned}=100^{\circ}$
Verify applicable prerequisites from Section 7 have been completed.

Start WRSS DAS software and log in as Operator.

Insert a floppy disk containing an ENRAF density meter data file into the DAS PC.

Go to the AY-102 DENSITY PROFILE screen (F2, Alt-D). Click the READ

DENSITY PROFILE button. Verify that data appears in each field on the screen.

Print the screen by clicking the printer icon at the bottom of the window.

16.5 Log in as System Engineer. Go to the TEST page (Ctr-Alt-T). Open Windows NT

Explorer. Open the density meter data file in Notepad (C:IWINNTINOTEPAD.EXE) and verify the sampling date, level, and density data are correct, NOTE: Density values in the data file correspond to specific gravity units/on the printed page

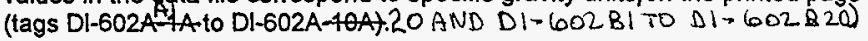

Open the density meter report file (C:ICITECTDATAIDENSITY.CSV) and verify the most recent data (both specific gravity and percent solids) is recorded in the

VERIFY

Using the following formula form Section 4.1.1 of the WRSS PCP, eheck the calculated value for $\mathrm{DI}-602 \mathrm{~A}-\mathrm{SO}$. The formula assumes that $\mathrm{DI}-602 \mathrm{~A}-1 \mathrm{~A}$ thas zero solids toading and uses $2.28 \mathrm{~g} / \mathrm{mt}$ as the density of the selid stutge-) (REPLACE THE

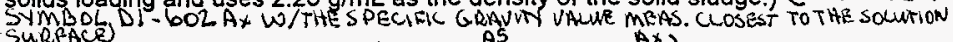

$\left[2.28^{\circ}\left(D 1-602 A^{A}-5 A-D 1-602 A^{A}+A\right]\right.$

I [DI-602A-5A $-(2.28-D I-602 A-4 A)]$

\section{END OF SECTION 16}


17 TANK AY-102 VENTILATION (MICON DCS) DATA FILE I/O (HNF-2115, \$ 3.1.3.4-5)

Tests access to data in DBF file on MICON DCS server in 241-AZ-271 (W-030 Control Room).

$2+2-2-98$ $p+4-2.98$ ex $4-2-98$

\section{$2+4-243$}

D.4-298

L) $4-2-94$
17.1 Verify applicable prerequisites from Section 7 have been completed.

17.2 Go to the OVERVIEW screen and $\log$ in as System Engineer.

17.3 Go to the AY-102 HVAC STATUS screen (F2, Alt-V). Verify that data appears in each field and that the data is updated at least every 12 minutes. Print the screen by clicking on the printer icon at the bottom of the window.

"MS-DOS PROMPT"

17.4 Go to the TEST page (Ciri-AIt-T). Click VIEW HWAG SNAPSHOF. A

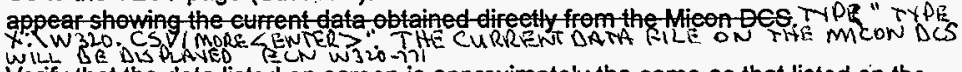

17.5 Verify that the data listed on screen is approximately the same as that listed on the screen print.

MS-DOSWWDow ECN w-320-77!

17.6 Close the HWAE-SNAPSHOF view and retum to the DAS. Log out of the DAS.

END OF SECTION 17 
SECTIONS 18 - 23

\section{FIELD TESTS FOR PLC FUNCTIONALITY}


The following tests for appropriate point mapping for all tank thermocouples (TI-01 - TI-93) listed in Data Sheet 9.3. Alarm set/reset points and ranges are tested for DAS thermocouples required by HNF-SD-WM-PCP-013, the WRSS Process Control Plan (p. 4-32). Where only one thermocouple of a given category is required, one extra is tested as a backup.

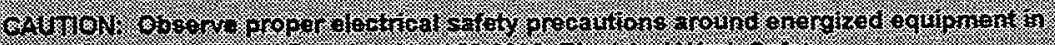

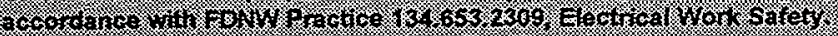

NOTE: The Westronics SDI-310 will not be fully tested in this procedure. It was previously tested by operations.

At3-28-95 18.1. Verify applicable prerequisites from Section 7 have been completed.

lt3-25-98 18.2 Go to the AY-102 TANK TEMPERATURES screen (F2, Alt-T). (Reference

Figure S-8, HNF-2115)

\subsection{VALID DISPLAYIPOINT MAPPING VERIFICATION}

Lt A-9-98 18.3.1 Verify that no invalid readings appear for any thermocouple functional category on

EXCEPTION 1

ECN $W-320-798$

the AY-102 TANK TEMPERATURES screen. A reading shall be considered invalid if it is less than $50^{\circ} \mathrm{F}$ or greater than $250^{\circ} \mathrm{F}$, or if any error code is displayed in place of a value. Record any invalid readings in Data Sheet 18.3.1; use extra sheets if required:

\begin{tabular}{|l|c|c|c|}
\hline \multicolumn{3}{|c|}{ DATA SHEET 18.3.1 - LIST INVALID READINGS FROM SDI-310 } \\
\hline TAG NAME & INVALID READING & TAG NAME & INVALID READING \\
\hline TE -72 & RANGE & & \\
\hline & & & \\
\hline & & & \\
\hline
\end{tabular}

Lt A.9.98 18.3.2 APply- POSITIV LEADON FCN-W720-79. for the AY-102 thermocouples in Data Sheet 9.3. Check for display errors in the expected tag, and record exceptions with the expected and actual display tag (if known) in Data Sheet 18.3.2.

NOTE: The jumper must be applied for a minimum of 10 seconds. Use ECN 639745 as a reference for terminal selection.

\begin{tabular}{|c|c|c|c|c|}
\hline \multicolumn{3}{|c|}{ DATA SHEET 18.3.2 - LIST INVALID POINT MAPPING FOR SDI-310 } \\
\hline \hline EXPECTED TAG NAME & ACTUAL & EXPECTED TAG NAME & ACTUAL \\
\hline & & & \\
\hline & & & \\
\hline & & & \\
\hline
\end{tabular}


NOTE: Complete the following steps for each of the thermocouples listed in Data Sheet 18.4. Use ECN 639745 as a reference for terminal connections.

\begin{tabular}{|c|c|c|}
\hline \multicolumn{3}{|c|}{ DATA SHEET 18.4 - THERMOCOUPLES TO BE FULLY VERIFIED } \\
\hline CATEGORY & APPLICABLE TEMP. ELEMENTS (TE-102-XX) & SETPOINTS ( $\left.{ }^{\circ} \mathrm{F}\right)$ \\
\hline DOMESPACE & $\begin{array}{l}60,66 \text { (RISERS } 13 \text { A AND 13C, AT } 300^{\prime \prime} \text { FROM } \\
\text { TANK BOTTOM) }\end{array}$ & $H: 120$ \\
\hline SLUDGE & $\begin{array}{l}62,68 \text { (RISERS } 13 \text { A AND 13C, AT 4" FROM } \\
\text { TANK BOTTOM) }\end{array}$ & $\mathrm{H}: 150, \mathrm{HH}: 195$ \\
\hline INS. CONCRETE & $1,3,6,10,14,24$ ECN-W320-798 & NONE \\
\hline SUPERNATE & $\begin{array}{l}61,67 \text { (RISERS 13A AND 13C, AT 158" FROM } \\
\text { TANK BOTTOM) }\end{array}$ & $\mathrm{H}: 150 ; \mathrm{HH}: 195$ \\
\hline
\end{tabular}

18.4.1 Record the current reading for the selected TC in the appropriate location in Data Sheet 18.4.1.

18.4.2 Disconnect TC listed in Data Sheet 18:4.1 from the terminals on the Westronics SDl-310 wiring block.

18.4.3 Connect TC simulator (Type J) to the terminals disconnected in Step 18.4.2.

18.4.4 Apply a signal equivalent to $70^{\circ} \mathrm{F}$, verify response on Tank AY-102 tank temperatures screen is $70 \pm 4^{\circ} \mathrm{F}$ and record response in the appropriate location in Data Sheet 18.4.1.

18.4.5 For TCs 60 AND 66: Apply a signal equivalent to $110^{\circ} \mathrm{F}$, then increase slowly until the HIGH alarm trips. Record alarm trip point from the alarm notification window in the appropriate location in Data Sheet 18.4.1. FOR TCs $61,62,67$, 68: Apply a signal equivalent to $140^{\circ} \mathrm{F}$, then increase slowly until the HIGH alarm trips. Record alarm trip point from the alarm notification window in the appropriate location in Data Sheet 18.4.1.

18.4.6 For TCs $60,61,62,66,67$, and 68: Verify that the alarm symbol is flashing AMBER and buzzer is sounding. Acknowledge the alarm by clicking on the flashing display symbol. The symbol will stop flashing. Decrease the input signal until the alarm symbol retums to normal. Verify that the alarm resef point is at least $4^{\circ} \mathrm{F}$ less than the HIGH setpoint listed in Data Sheet 18.4.1. Record the alarm reset point in the appropriate location in Data Sheet 18.4.1.

18.4.7 Apply a signal equivalent to $185^{\circ} \mathrm{F}$, verify response on DAS screen is $185 \pm 4^{\circ} \mathrm{F}$ and record response in the appropriate location in Data Sheet 18.4.1.

18.4.8 For TCs $61,62,67,68$ : Slowly increase the signal until the HIGH HIGH alarm trips. Record alarm trip point from the alarm notification window in the appropriate location in Data Sheet 18.4.1.

18.4.9 For TCs $61,62,67,68$ : Verify that the alarm symbol is flashing RED and chime is sounding. Acknowledge the alarm by clicking on the flashing display symbol. The 
symbol will stop flashing. Decrease the input signal until the HIGH HIGH alarm clears and the HIGH alarm trips. Verify that the alarm reset point is at least $4{ }^{\circ} \mathrm{F}$ less than the HIGH HIGH setpoint listed in Data Sheet 18.4. Record the alarm reset point in the appropriate location in Data Sheet 18.4.1.

ft 3-30-49 18.4.10 Disconnect simulator connected in Step 18.4.3.

LS3-30-98 18.4.11 Reconnect TC to the terminals disconnected in Step 18.4.2.

At 3-30.95 18.4.12 Verify reading on DAS screen is approximately the same as that recorded in Step 18.4.1.

\begin{tabular}{|c|c|c|c|c|c|c|c|c|}
\hline \multirow{2}{*}{$\begin{array}{c}18.4 .21 \\
18.4 .3 \\
T C \# \\
(T E- \\
102-X X) \\
\end{array}$} & \multirow{2}{*}{$\begin{array}{c}\mathbf{1 8 . 4 . 1} \\
\text { INITIAL } \\
\text { READING }\end{array}$} & \multicolumn{2}{|c|}{ RESPONSE TO INPUT } & \multicolumn{2}{|c|}{ ALARM TRIP } & \multicolumn{2}{|c|}{ ALARM RESET } & \multirow[b]{2}{*}{$\begin{array}{r}\text { INITLAL } \\
\text { DATE } \\
\end{array}$} \\
\hline & & $\begin{array}{c}18.4 .4 \\
\text { AT } 70^{\circ} \mathrm{F}\end{array}$ & $\begin{array}{l}18.4 .7 \\
\text { AT }^{185^{\circ} \mathrm{F}}\end{array}$ & $\begin{array}{l}18.4 .5 \\
\text { HIGH } \\
\end{array}$ & $\begin{array}{c}18.4 .8 \\
\text { HIGH HIGH } \\
\end{array}$ & $\begin{array}{l}18.4 .6 \\
\mathrm{HIGH} \\
\end{array}$ & $\begin{array}{c}18.4 .9 \\
\text { HIGH HIGH }\end{array}$ & \\
\hline 1 & 81.0 & 20.0 & 184.0 & & & & & $k+3-3098$ \\
\hline 2 & 80.0 & 20.0 & 184.0 & & & & & $R+3-30-98$ \\
\hline 6 & 87.0 & 20.0 & 183.0 & & & & & $k+3-3099$ \\
\hline 10 & 22.0 & 69.0 & 182.0 & & & & & $R+3-30-98$ \\
\hline 14 & 71.0 & 23.0 & 184.0 & & & & & $a_{r}-30.99$ \\
\hline 24 & 68.0 & 70.0 & 184.0 & & & & & $R_{0}-3-30.98$ \\
\hline 60 & 63.0 & 68.0 & 183.0 & 121.0 & & 113.0 & & $2 \times 3-30-48$ \\
\hline 66 & 63.0 & 69.0 & 184.0 & 121.0 & & 115.0 & (3) & $l_{+3-3098}$ \\
\hline 61 & 63,0 & 69.0 & 183.0 & 151.0 & 196,0 & 144.0 & 189.0 & R-3-3098 \\
\hline 62 & 70.0 & 70.0 & 183.0 & 151.0 & 1960 & 145.0 & 190.0 & $R+3-30-98$ \\
\hline 67 & 64.0 & 69.0 & 184.0 & 151.0 & 197.0 & 145.0 & 189.0 & $R+3-3098$ \\
\hline 68 & 68.0 & 68.0 & 182.0 & 151.0 & 197.0 & 145.0 & 190.0 & $2+3-30.98$ \\
\hline 3 & 78.0 & 20.0 & 185.0 & & & & & l+4-948 \\
\hline
\end{tabular}

END OF SECTION 18 
The following simulates thermocouple inputs to the DAS display, TI-06230 to TI-06251. Simulation of thermocouples TE-06240 failure will be performed to verify out of range behavior reading on the DAS display.

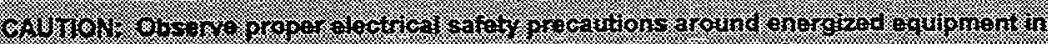

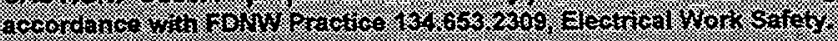

R+3.26-98

19.1 Verify applicable prerequisites from Section 7 have been completed.

R+326-98

19.2

Go to the OVERVIEW screen and $\log$ in as Operator. Go to the MIT screen (F2, Alt-M)

19.3 Perform the following for each thermocouple listed in Data Sheet 19.3.

19.3.1 Record initial reading from DAS MIT screen.

19.3.2 Disconnect TC from the terminals listed.

19.3.3 Connect TC simulator to the terminals of Step 19.3.2.

19.3.4 Apply a signal equivalent to $70^{\circ} \mathrm{F}$, verify response on DAS MIT screen is $70 \pm 4^{\circ}$ $F$ and record the DAS response value.

19.3.5 Slowly INCREASE the signal to $90^{\circ} \mathrm{F}$, verifying that the measured resolution is better than $0.1^{\circ} \mathrm{F}$ (verify step size $<=0.1$ ). Record the resolution.

19.3.6 For TE-06230; apply a signal equivalent to $110^{\circ} \mathrm{F}$.

19.3.7 For TE- 06234 through TE- 06254 apply a signal equivalent to $140^{\circ} \mathrm{F}$.

19.3.8 Switch to the DAS ALARMS screen (function key F6). INCREASE the input signal until the HIGH alarm trips. This will cause a buzzing sound to play, a message window to appear, and a flashing AMBER annunciator window. Record the HIGH alarm trip temperature.

19.3.9 Click DISMISS on the message window. Acknowledge the alarm. The annunciator window will stop flashing and the alarm sound will stop. Slowly DECREASE the input signal until the HIGH alarm resets. Verity that the reset temperature is at least 4 degrees less than the alarm trip temperature. Record the HIGH alarm reset temperature.

19.3.10 Switch to the MIT screen (function keys F2, Alt-M). Apply a signal equivalent to $185^{\circ} \mathrm{F}$, verify response on DAS MIT screen is $185 \pm 4^{\circ} \mathrm{F}$ and record response.

19.3.11 INCREASE the input signal until the HIGH HIGH alarm trips. This will cause a pulsating chime sound to play, a message window to appear, and a flashing RED annunciator window. Record the HIGH HIGH alarm trip temperature.

EXCEPT FOR TE-06251 ECN-W320-791.

19.3.12 Acknowledge the alarm. Slowly DECREASE the input signal until the HIGH HIGH alarm resets. Verify that the resef temperature is at least 4 degrees less than the alarm trip temperature. Record the HIGH alarm reset temperature. 
19.3.13 Reduce the input signal to less than the HIGH trip point determined in Step 19.3.8. Acknowledge the alarm. Verify that the alarms have cleared.

19.3.14 Disconnect simulator connected in Step 19.3.3.

19.3.15 Reconnect TC to the terminals disconnected in Step 19.3.2.

19.3.16 Verify reading from DAS MIT screen is approximately the same as that recorded in Step 19.3.1.

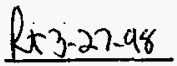

19.4 LITT THE NEGATVE LEAD

BCN w-320-7ר!

Ptace-a-shorting jumper-acress the teminals for TI-06240. Verify that the TI-6240 display shows RANGE on the DAS screen.

l+3-2798

19.5

RECONNELT LEAD LIETED

RECONN normal.

$2 \times 3.27 .94$

19.6

Go to the Alarm Log (press F6, then click the text icon at the left of the screen) and verify that the recent alarm activity appears at the bottom of the list. 


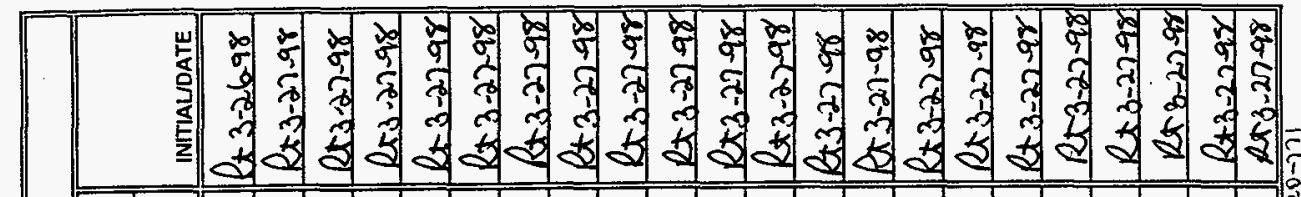

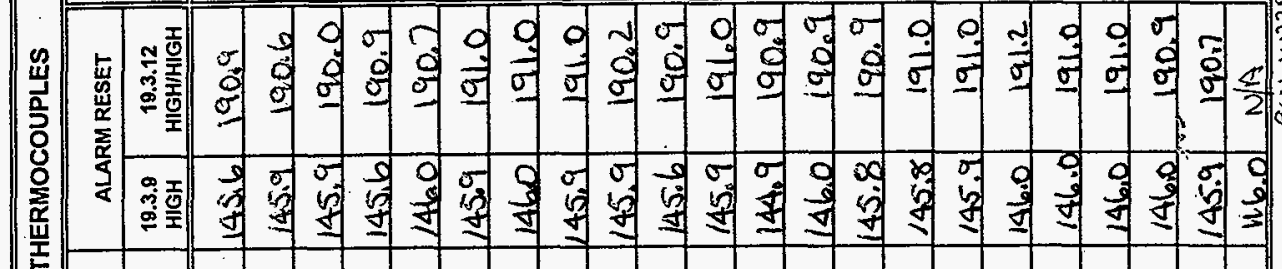

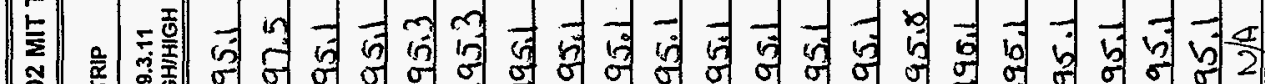

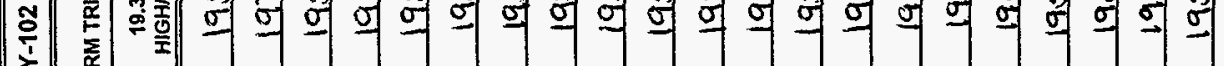

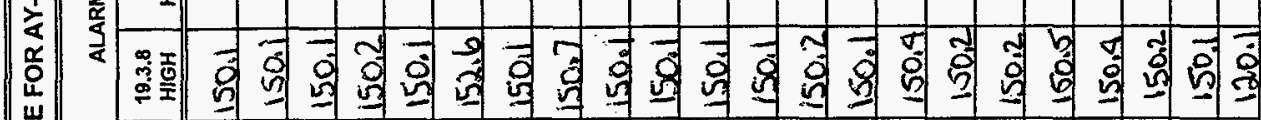

w

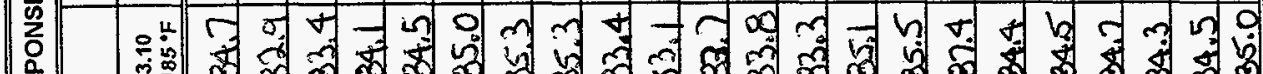

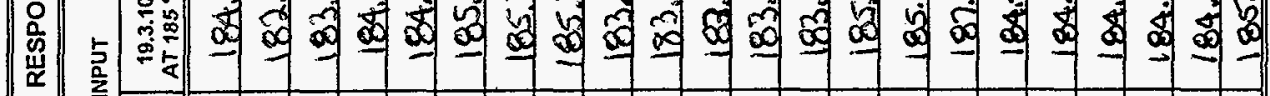

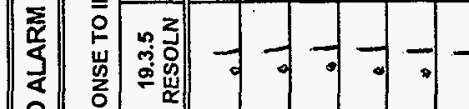

里

政

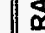

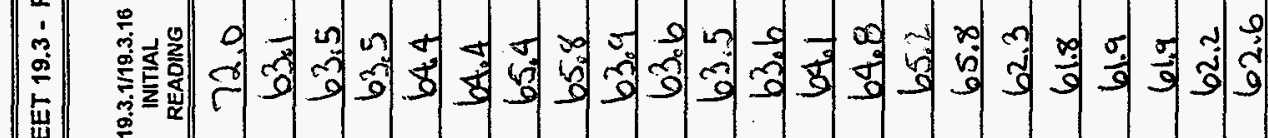

章

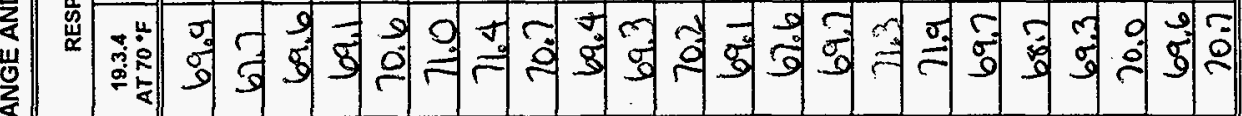

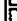

\begin{tabular}{|c|c|c|c|c|c|c|c|c|c|c|c|c|c|c|c|c|c|c|c|c|c|c|}
\hline 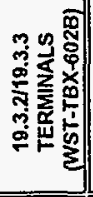 & 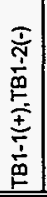 & 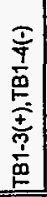 & 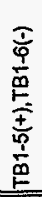 & 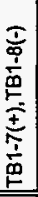 & 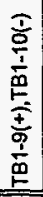 & 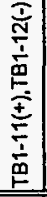 & 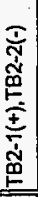 & 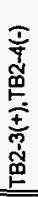 & 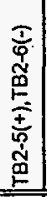 & 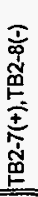 & 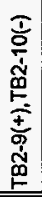 & 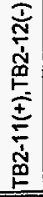 & 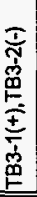 & 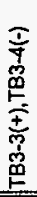 & 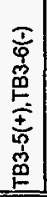 & 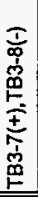 & 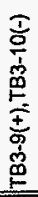 & 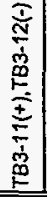 & 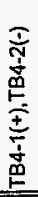 & 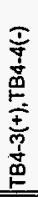 & 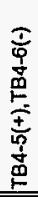 & 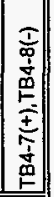 \\
\hline & 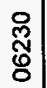 & $\begin{array}{l}\bar{S} \\
\text { S } \\
0\end{array}$ & $\begin{array}{l}\text { ֻै } \\
\text { ญे }\end{array}$ & 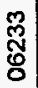 & 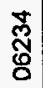 & 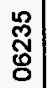 & 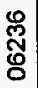 & 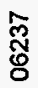 & 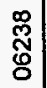 & $\begin{array}{l}\stackrel{9}{\mathcal{X}} \\
\mathbb{O} \\
\mathbb{O}\end{array}$ & $\begin{array}{l}\text { 웜 } \\
\text { ญ }\end{array}$ & $\begin{array}{l}\bar{む} \\
\text { ণ্ }\end{array}$ & $\begin{array}{l}\text { ฯั } \\
\text { ญั }\end{array}$ & 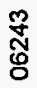 & 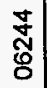 & $\begin{array}{l}\frac{1}{4} \\
\stackrel{8}{8}\end{array}$ & 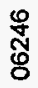 & $\begin{array}{l}\text { ¿ } \\
\text { \& }\end{array}$ & 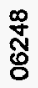 & $\begin{array}{l}\stackrel{9}{\grave{d}} \\
\text { ญু }\end{array}$ & $\begin{array}{l}\text { 융 } \\
\text { ญ् }\end{array}$ & 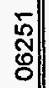 \\
\hline
\end{tabular}


The following tests the Tank 241-AY-102 Annulus Exhaust Flow and Temperature, Primary Tank Hydrogen, Primary Tank Exhaust Moisture and Tank Level by simulation.

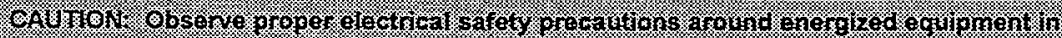

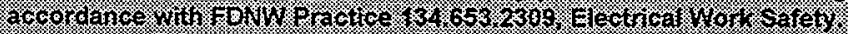

D.

K $3-3198$ 20.1 Verify applicable prerequisites from Section 7 have been completed.

\subsection{TANK 241-AY-102 ANNULUS EXHAUST FLOW (FIT-0622)}

The following will test by simulating the Tank 241-AY-102 Annulus Exhaust Flow to ascertain'that the transmitter and the DAS functions.

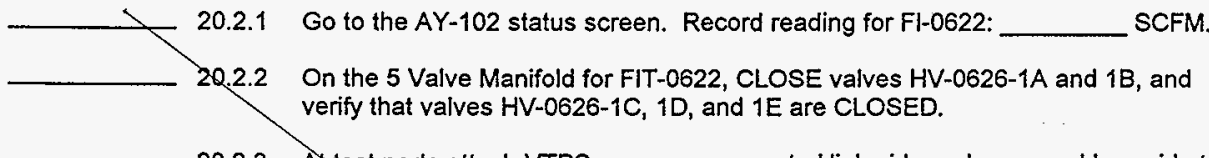

20.2.3 Attest ports attach VTPS pressure source to High side and open and Low side to atmosphere.

20.2.4 Go to the AX-102 STATUS screen.

20.2.5 Set VTPS to 0.140 inches $\mathrm{H}_{2} \mathrm{O}$.

20.2.6 Verify flow reading on DAS (FI-0622) is approximately the same as that shown locally at the FIT. Record DAS response: SCFM. Record FIT-0622 response SCFM.

20.2.7 Set VTPS to 0.050 inches $\mathrm{H}_{2} \mathrm{O}$.

Delate per Eck 798

20.2.8 Verify flow reading on DAS (FI-0622) is approximately the same as that shown locally at the FIT. Record DAS response: FIT-0622 response: SCFM. SCFM. Record

20.2.9 Set VTPS to 0.000 inches $\mathrm{H}_{2} \mathrm{O}$.

20.2.10 Verify flow reading on DAS (FI-0622) is approximately the same as that shown locally at the FIT. Record DAS response: FIT-0622 response: SCFM. SCFM. Reserd

20.2.11 Remove the VTPS at FIT-0622 on the 5 Valve Manifold, and recap the test ports. OPEN HV-0626-1A and $1 \mathrm{~B}$.

\subsection{TANK 241-AY-102 ANNULUS EXHAUST TEMPERATURE (TIT-0620)}

The following will test by simulating the Tank 241-AY-102 Annulus Exhaust Temperature to ascertain that the transmitter and the DAS functions.

20.3.1 Go to the AY-102 status screen. Record the current reading for TI-0620: $105.6{ }^{\circ} \mathrm{F}$. 


\section{3a. Description of Change}

1 HNF-1827 (QTP/ATP):

a. On Page 35, ADD Section 20.2 as follows: [Affects ECN W-320-798]

\subsection{TANK 241-AY-102 ANNULUS EXHAUST FLOW (FIT-0622)}

The Following will test by simulating the Tank 241-AY-102 Annulus Exhaust

Flow to ascertain that the transmitter and the DAS functions as designed.

\section{7 /18/98 20.2.1}

Go to the AY-102 status screen on DAS. Record current reading for FI-0622: 0.5 SCFM.

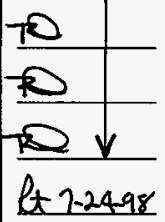

20.2.2 At FIT-0622, Record the current reading:

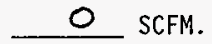

20.2.3 On FIT-0622 Enclosure, verify AC/HTR POWER ON light is LIT.

20.2.4 On FIT-0622 Enciosure, verify HEAT TRACE POWER ON 1 ight is LIT.

20.2 .5

At TE/TC-0625, simulate low ambient temperature by spraying temperature probe TE-0625 with canned refrigerant/circuit cooler until the Heat Trace on instrument tubing $1 / 4 " 1-750-131$ and 1/4"1-751-131 is energized by verifying Heat Trace monitor lights YL-06230 and YL06231 illuminate.

Rt7-24.98 20.2.6 Allow enough time for temperature probe TE-0625 to warm up to ambient temperature (assumed to be greater than $50{ }^{\circ} \mathrm{F}$ ) until the Heat Trace lights YL-06230 and YL06231 extinguish.

$7 / 18 / 9820.2 .7$ At FIT-0622 Enclosure, record reading for TI-0620: $85{ }^{\circ} \mathrm{F}$. Verify that TI-0620 is within the range of $45-87^{\circ} \mathrm{F}$.

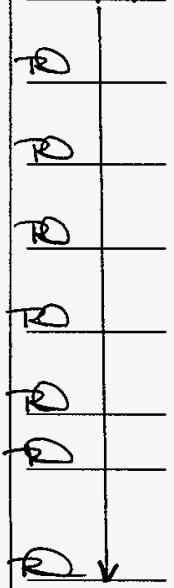

20.2.8 On 5-Valve Manifold for FIT-0622, close valves HV-0626-1A and 1B, and verify that valves HV-0626-1C, 10 and $1 \mathrm{E}$ are CLOSED.

20.2.9 In FIT-0622 Enclosure, verify valves HV-06230 and HV-06231 are OPEN.

20.2.10 In FIT-0622 Enclosure, verify valves HV-06232 and HV-06233 are CLOSED.

20.2.11 At FIT-0622 test ports, attach VTPS (variable test pressure source) to High side on 5-Valve Manifold. Vent Low side to atmosphere. VTPS $\$ 17-13$-01-020 DUE: $1-21-99$

20.2.12 Set VTPS to 0.000 inches $\mathrm{H}_{2} \mathrm{O}$.

20.2.13 Verify flow reading on DAS (FI-0622) is \pm 10 SCFM of that shown locally at FIT-0622. Record DAS response: 0.5 SCFM. Record FIT-0622 response: 0 SCFM.

20.2.14 Set VTPS to 0.025 inches $\mathrm{H}_{2} \mathrm{O}$. 


\section{Tro $718 / 98 \quad 20.2 .15$}

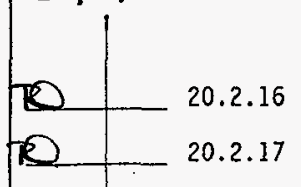

Verify flow reading on DAS (FI-0622) is \pm 10 SCFM of that shown 1ocally at FIT-0622. Record DAS response: 734 SCFM. Record FIT-0622 response: 125 SCFM.

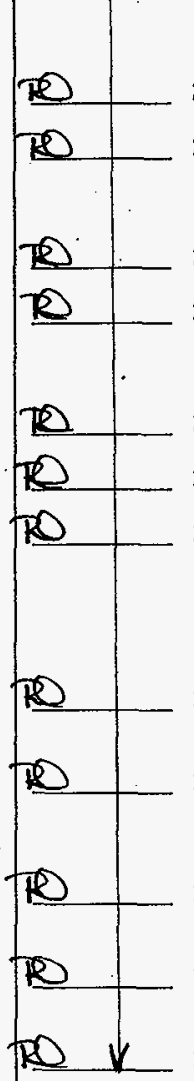

20.2.18 Set VTPS to 0.075 inches $\mathrm{H}_{2} \mathrm{O}$.

20.2.19 Verify flow reading on DAS (FI-0622) is \pm 10 SCFM of that shown locally at FIT-0622. Record DAS response: 1384 SCFM. Record FIT-0522 response: 1382 SCFM.

20.2.20 Set VTPS to 0.100 inches $\mathrm{H}_{2} \mathrm{O}$.

20.2.21 Verify flow reading on DAS (FI-0622) is \pm 10 SCFM of that shown locally at FIT-0622. Record DAS response: 1617 SCFM. Record FIT-0622 response: 1614 SCFM.

20.2.22 Set VTPS to 0.050 inches $\mathrm{H}_{2} \mathrm{O}$.

20.2.23 Go to DAS ALARMS screen (F6). Acknowledge all active alarms (F12).

20.2.24 Slow7y DECREASE VTPS input until the LOW alarm trips. This will cause a sound to play, a message window to appear, and a flashing. AMBER annunciator window. Verify alarm trip point is 700 SCFM (680-720 SCFM). Record from DAS the LOW alarm trip point listed in message window: 687 SCFM.

20.2.25 Click DISMISS on the message window. Acknowledge the alarm. The annunciator will stop flashing and the alarm sound will stop.

20.2.26 SlowTy INCREASE VTPS input until the LOW alarm clears. VERIFY al arm reset point is 800 SCFM (780-820 SCFM). Record from DAS the LOW a arm reset point: 815 SCFM.

20.2.27 Remove the VTPS from the 5-Valve Manifold, and recap the test ports, OPEN HV-0626-1A and $1 B$.

20.2.28 Verify reading for FI-0622 on DAS is approximately the same as that recorded in Step 20.2.1. Record reading: 0.5 SCFM

20.2.29 Verify reading on FIT-0622 is approximately the same as that recorded in Step 20.2.2. Record Reading: $O$ SCFM. 


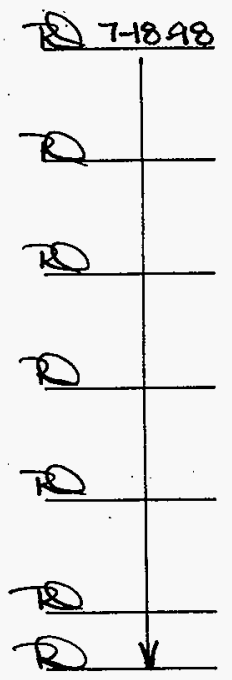

20.3.2

At the Tank 241-AY-102 Annulus Exhaust Duct and on TIT-0620, record the current reading on TIT-0620 $107.0{ }^{\circ} \mathrm{F}$. Disconnect RTD wires from TE-0620. Connect RTD simulator.

20.3.3 Increase RTD temperature to $200^{\circ} \mathrm{F}$. Verify TI-0620 indication on DAS equals RTD simulator value $\pm 4^{\circ} \mathrm{F}$. Verify TIT-0620 (local indication) equals TI-0620 (DAS) $\pm 4^{\circ} \mathrm{F}$. Record results from DAS: $197.7^{\circ} \mathrm{F}$.

20.3.4 Decrease RTD to $175^{\circ} \mathrm{F}$. Verify TI-0620 indication on DAS equals RTD simulator value $\pm 4^{\circ} \mathrm{F}$. Verify TIT-0620 (local indication) equals TI-0620 (DAS) $\pm 4^{\circ} \mathrm{F}$. Record results from DAS: $173.6^{\circ} \mathrm{F}$.

20.3.5 Decrease RTD to $150^{\circ} \mathrm{F}$. Verify TI-0620 indication on DAS equals RTD simulator value $\pm 4^{\circ} \mathrm{F}$. Verify TIT-0620 (local indication) equals TI-0620 (DAS) $\pm 4^{\circ} \mathrm{F}$. Record results from DAS: $47.9^{\circ} \mathrm{F}$.

20.3.6 Decrease RTD to $125^{\circ} \mathrm{F}$. Verify TI-0620 indication on DAS equals RTD simulator value $\pm 4^{\circ} \mathrm{F}$. Verify TIT-0620 (local indication) equals TI-0620 (DAS) $\pm 4^{\circ} \mathrm{F}$. Record results from DAS: $123.6^{\circ} \mathrm{F}$.

20.3.7 Disconnect RTD simulator from TIT-0620 and reconnect TE-0620 RTD wires.

20.3.8 Verify TI-0620 (DAS) and TIT-0620 reading is approximately the same as that recorded in Steps 20.3.1 and 20.3.2.

20.4 PRIMARY TANK 241-AY-102 DOME HYDROGEN (NIT-02JAY-12-1)

The following will test by simulating the Primary Tank 241-AY-102 Dome Hydrogen to ascertain that the transmitter signal and the DAS functions.

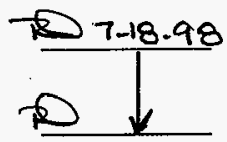

20.4 .1

Go to the AY-102 STATUS screen. Record the current reading for Al-0621: Q10\%.LFL REN W $320-198$ ECN w320-798 /

20.4.2 In the SHMS Enclosure for Tank 241-AY-102, record current reading for NIT-) $02 J A Y-12-1: 0,00 \%$. Verify the reading is approximatelyfthe same as of that recorded in Step 20.4.1. Disconnect transmitter lead wiring NR-02JAY-12-1 and NIT-02JAY-12-1 from terminals 9 and 10 on terminal block TB2.

B 20.4.2.

NOTE: Acknowledge and reset alarms generated during Steps 20.4.4 through 20.4.6. D大 $7-28.98$ 20.4.4 Apply $8.00 \mathrm{~mA}$, verify response on DAS screen falls within the tolerance of $25 \pm$ $1 \%$, and record results from DAS: $10.00 \%$.

20.4.5 Apply $12.00 \mathrm{~mA}$. Slowly increase the signal, and verify the measured step size is less than the maximum of $0.1 \%$. Record the resolution from DAS:

BunW320-798

20.4.6 Apply 16.00 $\mathrm{mA}$, verify response on DAS screen falls within the tolerance of $75 \pm 320$ $1 \%$, Record results from DAS: $\mathbf{3 0 . 0 1} \%$.

20.4.7 Go to the DAS ALARMS screen (F6). Acknowledge any active alarms (F12).

20.4.8 Apply $4 \mathrm{~mA}$, then INCREASE the input signal until the HIGH alarm trips. This will cause a sound to play, a message window to appear, and a flashing AMBER annunciator window. Record results from DAS the HIGH alarm trip point listed in 
the message window: $|0| \$,$% (should be 10\%). Record results from the$ transmitter simulator. $10,50 \mathrm{~mA}$.

Rt 4 1-98 20.4.9 Click DISMiss on the message window. Acknowledge the alarm. The annunciator window will stop flashing and the alarm sound will stop.

Rt 4-1-98 20.4.10 Slowly decrease input until HIGH alarm clears. Record reset point from DAS: $7.99 \%$. Verify that the reset point is no greater than $8 \%$ Record current reading from the transmitter simulator: $9.11 \mathrm{~mA}$.

(9.6) ECN w320.812

$R+4-1-98$

20.4.11 INCREASE the input signal past the HIGH alarm setpoint and until the HIGH HGH alarm trips. This will cause a different sound to play, a message window to appear, and a flashing REQ annunciator window. Record results from DAS the HIGH HIGH alarm trip point listed in the message window: $25.2 \%$ (should be $25 \%$ ). Record results from the transmitter simulator: $20.1 \mathrm{~mA}$.

h+4-1-98

20.4.12 ISMISS on the message window. Acknowledge the alarm. The

R+4-1-98 annunciator window will stop flashing and the alarm sound will stop.

20.4.13 Slowly decrease input until HIGH HIGH alarm clears. Record reset point from PAS: $22.96 \%$. Verify that the reset point is no greater than $23 \%$. Record current reading from the transmitter simulator: $18.2 \mathrm{~mA} .(24.6\}$ EON W-320.812

Q.4-198 20.4.14 Verify that the HIGH alarm trips after the HIG HIGH alarm resets.

R+4-198 20.4.15 DECREASE the input signal to $5 \mathrm{~mA}$ and DO NOT acknowledge any alarms. Verify that the unacknowledged HIGH alarm does hot clear and is listed on the ALARM SUMMARY screen.

Lt 4-1.98 20.4.16 Disconnect transmitter simulator installed in Step 20.4.3. FOR RE-RUN \#f $73^{\circ 98}$ Rr 4 - 20.48 Reconnect transmitter lead wiring to terminals disconnected in Step 20.4.2. A) 4-1-98 20.4.18 Verify reading on DAS and NIT-02JAY-12-1 is is SIMLALR TO ECN W-320-798 20.4.1 and 20.4.2, respectively.

20.5 TANKAY-102 LEVEL MONITORING (LIT-602A) SIMULATION

NOTE: The ENRAF LEVEL GAUGE will not be tested in this procedure. It was tested in 6-TF125 (HNF-SD-ATP-023).

R+ $4-1-98$

20.5.1 Go to the AY-402 STATUS screen. Record the current reading for LI-602C: 114,37 inches; WST-LIT-602A (TK-241-AY-102, Riser 22A): 99999 inches; LI-602A (2750E Bldg): 222.91 inches; and LI-602B (241-AY-51): 114.6 inches. SEE PAGE 37A FOR RERUN $P_{7-30-78}$

Rt $4-1-9820.5 .2$ In the WST-TBX-602A, disconnect transmitter lead wiring from terminals TB 1-1 and TB1-2.

h+ 4-1-98 20.5.3 Connect transmitter simulator (4-20 mA source) to terminal of Step 20.5.2.

R-4 - 20.5.4 Apply $8.00 \mathrm{~mA}$, verify response on DAS screen falls within the tolerance of 165 \pm 1 inch, and record results from DAS: 164.89 inches and LI-602B: 165.0 inches.

Rt 4-198 20.5.5 Apply $12.00 \mathrm{~mA}$ and record results from DAS: 209.91 inches and LI-602B: 210.0 inches. Slowly increase the signal, and verify the measured step size is

W320DAS.ATP

-37 -

HNF-1828, Rev. 0

Page 39 
the message window: $10.0 \%$ (should be $10 \%$ ). Record results from the transmitter simulator: $\frac{1}{8} \mathrm{~mA}$.

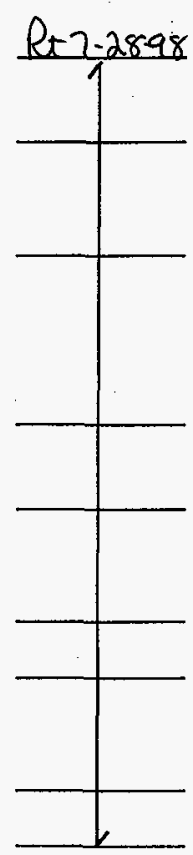

20.4.9

20.4.10

Click DISMISS on the message window. Acknowledge the alarm. The annunciator window will stop flashing and the alarm sound will stop.

Slowly decrease input unfil HIGH alarm clears. Record reset point from DAS: $9.57 \%$. Verify that the reset point is no greater than $8 \%$ Record current reading from the transmitter simulator: $7.83 \mathrm{~mA}$. (9.6) ECN w $320-812$

20.4.11 INCREASE the input. signal past the HIGH alarm setpoint and until the HIGH $\mathrm{HIGH}$ alarm trips. This will cause a different sound to play, a message window to appear, and a flashing RED annunciator window. Record results from DAS the HIGH HIGH alarm trip point listed in the message window: $2.5 .0 \%$ (should be $25 \%$ ). Record results from the transmitter simulator: $14,0 \mathrm{~mA}$.

20.4.12 Click DISMISS on the message window. Acknowledge the alarm. The annunciator window will stop flashing and the alarm sound will stop.

20.4.13 Slowly decrease input until HIGH HIGH alarm clears. Record reset point from DAS: $24,6 \%$. Verify that the reset point is no greater than $23 \%$. Record current reading from the transmitter simulator: $13.83 \mathrm{~mA}$. 24.6. EN w-320-412

20.4.14 Verify that the HIGH alarm trips after the HIGH HIGH alarm resets.

20.4.15 DECREASE the input signal to $5 \mathrm{~mA}$ and DO NOT acknowledge any alarms. Verify that the unacknowledged HIGH alarm does not clear and is listed on the ALARM SUMMARY screen.

20.4.16 Disconnect transmitter simulator installed in Step 20.4.3.

20.4.17 Reconnect transmitter lead wiring to terminals disconnected in Step 20.4.2.

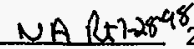
8
SIMILAR TO ELN W 320.797 Verify reading on DAS and NIT-02JAY-12-1 ts the-same-as that recorded in Steps 20.4.1 and 20.4.2, respectively.

\subsection{TANK AY-102 LEVEL MONITORING (LIT-602A) SIMULATION}

NOTE: The ENRAF LEVEL GAUGE will not be tested in this procedure. It was tested in 6-TF125 (HNF-SD-ATP-023).

$R t=2898$ 20.5.1 Go to the AY-102 STATUS screen. Record the current reading for LI-602C: 167.22 inches; WST-LIT-602A (TK-241-AY-102, Riser 22A): 16.32 inches; LI-602A (2750E BIdg): 167.31 inches; and LI-602B (241-AY-51): 167.5 inches.

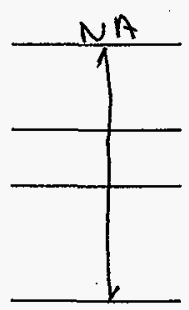

20.5.2

20.5 .3

20.5.4

20.5.5

In the WST-TBX-602A, disconnect transmitter lead wiring from terminals TB 1-1 and T81-2.

Connect transmitter simulator (4-20 mA source) to terminal of Step 20.5.2.

Apply $8.00 \mathrm{~mA}$, verify response on DAS screen falls within the tolerance of 165 \pm 1 inch, and record results from DAS: inches. inches and $\mathrm{LI}-602 \mathrm{~B}$ :

Apply $12.00 \mathrm{~mA}$ and record results from DAS: inches and $\mathrm{LI}-602 \mathrm{~B}$ : inches. Slowly increase the signal, and verify the measured step size is 
Pt 4-1986 20.5.6 Apply 16.00 mA, verify response on DAS screen falls within the tolerance of 255 \pm 1 inch, and record results from DAS: 254.85 inches and LI-602B: 254.9 inches.

Bt 4-1-98 20.5.7 Go to the DAS ALARMS screen (F6).

ft 4-1-98 20.5.8 INCREASE the input signal until the HIGH alarm trips. This will cause a sound to play, a message window to appear, and a flashing AMBER annunciator window. Record results from DAS the HIGH alarm trip point listed in the message window: 270.0 inches (should be 270 inches) and LI-602B: 270.1 inches. Record results from the transmitter simulator. $17.35 \mathrm{~mA}$.

R-4-1-98 20.5.9 Click DISMISS on the message window. Acknowledge the alarm. The annunciator window will stop flashing and the alarm sound will stop.

R 4-1-98 20.5.10 Slowly decrease input until HIGH alarm clears. Record reset point from DAS: 268.9 inches and LI-602B: 169.0 inches. Verify that the reset point is no greater than 269 inches. Record current reading from the transmitter simulator. $17.25 \mathrm{~mA}$.

RTA-198 20.5.11 INCREASE the input signal past the HIGH alarm setpoint and until the HIGH HIGH alarm trips. This will cause a different sound to play, a message window to appear, and a flashing RED annunciator window. Record results from DAS the HIGH HIGH alarm trip point listed in the message window: 280.0 inches (should be 280 inches) and LI-602B: 280.1 inches. Record results from the transmitter simulator: $18.24 \mathrm{~mA}$.

R A-198 20.5.12 Click DISMISS on the message window. Acknowledge the alarm. The annunciator window will stop flashing and the alarm sound will stop.

L $4-1-98$ 20.5.13 Slowly decrease input until HIGH HIGH alarm clears. Record reset point from DAS: 279 . Dinches and LI-602B: 278.1 inches. Verify that the reset point is no greater than 279 inches. Record current reading from the transmitter simulator. $18.15 \mathrm{~mA}$.

RtA-1-98 20.5.14 Verify that the HIGH alarm trips after the HIGH HIGH alarm resets.

R+4-198

20.5.15 DECREASE the input signal to $5 \mathrm{~mA}$. Go to the ALARM SUMMARY screen, and verify that the alarms list is in reverse chronological order. Acknowledge any active alarms.

Rt 4-198 20.5.16 Disconnect transmitter simulator installed in Step 20.5.3.

Rt4t-98 20.5.17 Reconnect transmitter lead wiring to terminals disconnected in Step 20.5.2.

LN 4-1-98 20.5.18 Verify readings on LI-602C (DAS), WST-LIT-602A, LI-602A and LI-602B are the same as that recorded in Step 20.5.1.

20.6 TANKAY-102 EXHAUST HUMIDITY MONITORING (AIT-0623) SIMULATION

Rt 3-319 20.6.1 Go to the AY-102 STATUS screen. Record the current reading for Al-0623 (DAS): 99.9\% AIT-0623: — \% at 241-AY-402. ESW W320 - — W 
$R+3-3198$

20.

20.6.2 In AY-102-JB-3S5, disconnect transmitter lead wiring and from terminals TB1-1 and TB1-2.

Rt 3-3198 20.6.3 Connect transmitter simulator (4-20 mA source) to terminals TB1-1 and TB!-2.

A $3-31.98$ 20.6.4 Apply $8.00 \mathrm{~mA}$, verify response on DAS screen falls within the tolerance of $25 \pm$ $1 \%$, and record results from DAS: $25,0 \%$.

Dt 3-31-98 20.6.5 Apply $12.00 \mathrm{~mA}$, verify response on DAS screen falls within the tolerance of $50 \pm$ $1 \%$, and record results from DAS: $50.0 \%$.

Rt 3-31-98 20.6.6 Apply $16.00 \mathrm{~mA}$, verify response on DAS screen falls within the tolerance of $75 \pm$ $1 \%$, Record results from DAS: $25,0 \%$.

$R+3-31-98 \cdot 20.6 .7$ Apply $12.00 \mathrm{~mA}$. Slowly increase the signal, and verify the measured step size is less than the maximum of $0.1 \%$. Record the resolution from DAS: $0.1 \%$.

(t-3-31-98 20.6.8 Disconnect transmitter simulator installed in Step 20.6.3.

$2+3-31-98$ 20.6.9 Reconnect transmitter lead wiring to terminals disconnected in Step 20.6.2.

Ar4998 20.6.10 Verify readings on DAS and local ATF-0623 ECW W $320-798-$ Step 20.6.1.

END OF SECTION 20 
f. On Page 40, delete and replace Section 21.2 as follows: [Affects ECN W-320-798]

\subsection{TANK 241-C-106 PRESSURE (PIT-1361) SIMULATION}

NOTE: PIT-1361 and PIC-1361 have been tested in HNF-SD-W320-ATP-012 in accordance with Step 16.3. Acknowledge any alarms generated during the steps in this section.

1-17.48 21.2.1 Go to the C-106 STATUS screen on DAS. Record current reading for

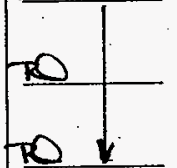

21.2.2 On CP-01, Record the current reading from PIC-1361:

- $\mathrm{O}$ inches $\mathrm{H}_{2} \mathrm{O}$.

21.2.3 ON IR-1361 in Process BIdg 241-C-91, Record the current reading

Exe $\frac{7-24-98}{5} 21.2 .4$ from PIT-1361: .976 inches $\mathrm{H}_{2} \mathrm{O}$.

Verify readings obtained in above steps are all within $+/-0.1$ inches $\mathrm{H}_{2} \mathrm{O}$ of each other.

TR 7-17-98

21.2 .5

In CP-01, disconnect transmitter (PIT-1361) lead wiring from terminals $T B-1-6$ and TB-1-7.

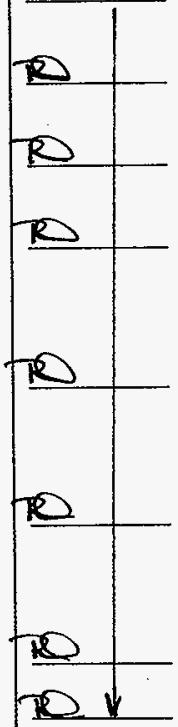

21.2.6 In CP-01, verify that TB-3 fuse block 4 is LIFTED/OPEN (this disables the evacuation horn PAL-1361B).

21.2.7 In CP-01, connect transmitter simulator (4-20. Ma source) to terminals $T B-1-6$ and $T B-1-7$. 2s 817-13-55-026 Dut: 3-30-99

21.2.8 Apply $8.00 \mathrm{Ma}$, verify response on DAS screen is -6.25 inches $\mathrm{H}_{2} \mathrm{O}$ $\left(-6.20\right.$ to -6.30 inches $\left.\mathrm{H}_{2} \mathrm{O}\right)$. Record results from DAS: -6.249 inches $\mathrm{H}_{2} \mathrm{O}$. Verify response on P.IC-1361 is -6.1 to -6.4 inches $\mathrm{H}_{2} \mathrm{O}$ ) Record results from PIC-1351: $=6.2$ inches $\mathrm{H}_{2} 0$.

21.2.9 Apply $12.00 \mathrm{Ma}$, verify response on DAS screen is -2.50 inches $\mathrm{H}_{2} \mathrm{O}$ $\left(-2.45\right.$ to -2.55 inches $\left.\mathrm{H}_{2} \mathrm{O}\right)$. Record results from DAS: -2.502 inches $\mathrm{H}_{2} \mathrm{O}$. Verify response on PIC-1361 is -2.4 to -2.6 inches $\mathrm{H}_{2} \mathrm{O}$ ) Record results from PIC-1361: $=2.5$ inches $\mathrm{H}_{2} \mathrm{O}$.

21.2.10 Apply 16.00 Ma, verify response on DAS screen is 1.25 inches $\mathrm{H}_{2} \mathrm{O}$ (1.20 to 1.30 inches $\mathrm{H}_{2} \mathrm{O}$ ). Record results from DAS: 1.249 inches $\mathrm{H}_{2} \mathrm{O}$. Verify response on $\mathrm{PIC}-1361$ is 1.1 to 1.4 inches $\mathrm{H}_{2} \mathrm{O}$ ) Record results from PIC-1361: $\frac{1.3}{1.3}$ inches $\mathrm{H}_{2} \mathrm{O}$.

21.2.11 Go to DAS ALARMS screen (F6). Acknowledge all active alarms (F12). 21.2.12 Apply $12 \mathrm{Ma}$, then INCREASE input signal until the LOW VACUUM/LOSS OF VACUUM al arms trip on DAS, PIC-1361 and ANN-1361 (window 1-2). This will cause a sound to play, a message window to appear, and a flashing AMBER annunciator window in DAS. 
27-18.98 21.2.13 on ANN-1361, acknowledge TANK 241-C-106 LOSS OF VACUUM (PAL-1361A) alarm (window 1-2).

21.2.14 On PIC-1361, acknowledge LOW VACUUM alarm.

Exc

21.2.15 Verify DAS alarm trip point is -0.30 inches $H_{2} 0 \quad(-0.25$ to -0.35 inches $\mathrm{H}_{2} \mathrm{O}$ ). Record from DAS the LOW VACUUM a] arm trip point listed in message window: $\mathrm{O}_{0} 29$ inches $\mathrm{H}_{2} \mathrm{O}$. Record transmitter simulator input value: $14.35 \mathrm{~mA}$.

R 7.18 .9821 .2 .16

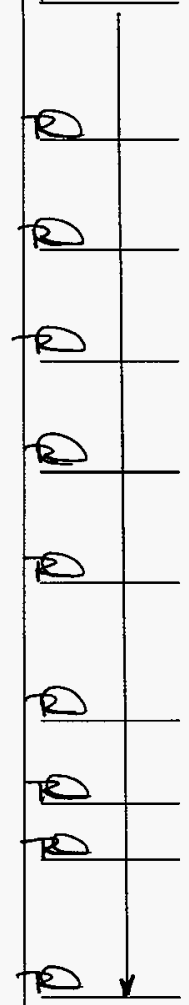

21.2.17 Click DISMISS on the message window on DAS. Acknowledge the a 1 arm. The annunciator window will stop flashing and the alarm sound will stop.

21.2.18 S1ow1y DECREASE input until LOW VACUUM/LOSS OF VACUUM alarms clear on DAS \& PIC-1361, and annunciator TANK 241-C-106 LOSS OF VACUUM (PAL-1361A) alarm (window 1-2) resets.

21.2.19 Verify DAS alarm reset point is -1.40 inches $\mathrm{H}_{2} \mathrm{O}(-1.35$ to -1.45 inches $\mathrm{H}_{2} \mathrm{O}$ ). Record reset point from DAS: -1.403 inches $\mathrm{H}_{2} \mathrm{O}$. Record transmitter simulator input value: $\overline{13.17} \mathrm{~mA}$.

21.2.20 Verify ANN-136I (window 1-2) reset point is -1.40 inches $\mathrm{H}_{2} \mathrm{O}(-1.30$ to -1.50 inches $\mathrm{H}_{2} 0$ ). Record reset point from PIC-1361: $=1.4$ inches $\mathrm{H}_{2} \mathrm{O}$. Record transmitter simulator input value: $13.20 \mathrm{~mA}$.

21.2.21 Apply 12 mA, then DECREASE input signal until the HIGH VACUUM/ EXCESSIVE VACUUM alarms trip on DAS, PIC-1361 and ANN-1361 (window 1-1). This will cause a sound to play, a message window to appear, and a flashing AMBER annunciator window in DAS.

21.2.22 On ANN-1361, acknowTedge TANK 241-C-106 EXCESSIVE VACUUM (PAH-1361A) alarm (window 1-1).

21.2.23 On PIC-1361, acknowledge HIGH VACUUM a]arm.

21.2.24 Verify DAS alarm trip point is -4.00 inches $\mathrm{H}_{2} \mathrm{O}(-3.95$ to -4.05 inches $\left.\mathrm{H}_{2} \mathrm{O}\right)$. Record from DAS the HIGH VACUUM al arm trip point listed in message window: -4.0 inches $\mathrm{H}_{2} 0$. Record transmitter simulator input value: $10 . \overline{4} \mathrm{~mA}$.

21.2.25 Verify ANN-1361 alarm trip point is -4.00 inches $(-3.90$ to -4.10 inches $\mathrm{H}_{2} \mathrm{O}$ ). Record from PIC-1361 the HIGH VACUUM al arm trip point: -4.0 inches $\mathrm{H}_{2} \mathrm{O}$. Record transmitter simulator input value: $10.4 \mathrm{~mA}$. 


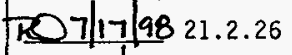
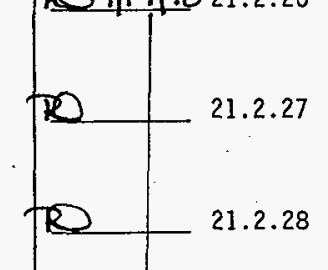

21.2 .28

Click DISMISS on the message window on DAS. Acknowledge the alarm. The annunciator window will stop flashing and the alarm sound will stop.

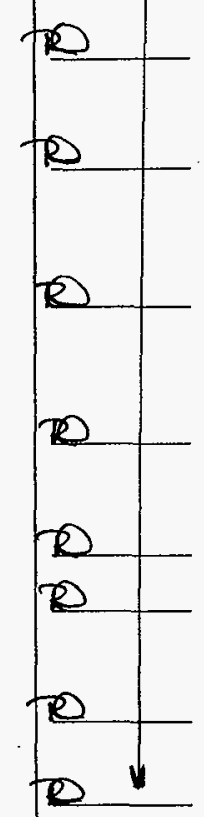

21.2 .29

Slowly INCREASE input unti1 HIGH VACUUM/EXCESSIVE VACUUM alarmS clear on DAS \& PIC-1361, and annunciator TANK 241-C-106 EXCESSIVE VACUUM (PAH-1361A) alarm (window 1-1) resets.

Verify DAS alarm reset point is -2.90 inches $\mathrm{H}_{2} \mathrm{O}(-2.85$ to -2.95 inches $\mathrm{H}_{2} \mathrm{O}$ ). Record reset point from DAS: -2.894 inches $\mathrm{H}_{2} \mathrm{O}$. Record transmitter simulator input value: $11.5 \mathrm{~mA}$.

Verify ANN-1361 (window 1-1) reset point is -2.90 inches $\mathrm{H}_{2} \mathrm{O}(-2.80$ to -2.90 inches $\mathrm{H}_{2} 0$ ). Record reset point from PIC-1361: $\underline{2.9}$ inches $\mathrm{H}_{2} \mathrm{O}$. Record transmitter simulator input value: $11.5 \mathrm{~mA}$.

21.2.30 DECREASE input signal past the HIGH VACUUM alarm until the HIGH HIGH VACUUM alarm trips on DAS. This will cause a sound to play, a message window to appear, and a flashing RED annunciator window in DAS.

21.2.31 Verify alarm trip point is -5.80 inches $H_{2} 0(-5.75$ to 5.85 inches $\mathrm{H}_{2} \mathrm{O}$ ). Record from DAS the HIGH HIGH VACUOM alarm trip point 7 isted in message window: -5.83 inches $\mathrm{H}_{2} \mathrm{O}$. Record transmitter simulator input value: $\mathbf{B . 4} \mathrm{mA}$.

21.2.32 Click DISMISS on the message window on DAS. Acknowledge the alarm. The annunciator window will stop flashing and the alarm sound will stop.

21.2.33 Slowly INCREASE input until HIGH HIGH VACUUM alarm clears on DAS.

21.2.34 Verify alarm reset point is -4.70 inches $\mathrm{H}_{2} \mathrm{O}(-4.65$ to -2.75 inches $\left.\mathrm{H}_{2} \mathrm{O}\right)$. Record reset point from DAS: -4.65 inches $\mathrm{H}_{2} \mathrm{O}$. Record transmitter simulator input value: $\frac{9.7}{9 A}$.

21.2.35 In CP-01, disconnect transmitter simulator from terminals $\mathrm{TB}-1-6$ and $T B-1-7$.

21.2.36 In CP-01, reconnect transmitter (PIT-1361) lead wiring to terminals TB-1-6 [wire PIT-1361-(+)] and TB-1-7 [wire PIT-1361-(-)].

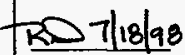

21.2 .37

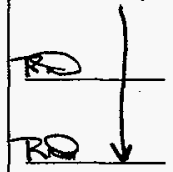

Verify reading on DAS is approximately the same as that recorded in Step 21.2.1.

21.2.38 Verify reading on $\mathrm{PIC}-1361$ is approximately the same as that recorded in Step 21.2.2.

21.2.39. Verify reading on PIT-1361 is approximately the same as that recorded in Step 21.2.3. 
The following tests will simulate the Tank C-106 Dome Pressure (PIT-1361), Booster Pump Discharge Pressure (PIT-1362), and Booster Pump Discharge Flow (FIT-13611).

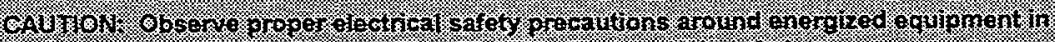

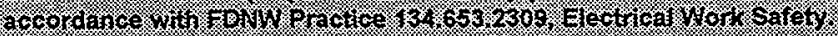

lt 3-21-98

21.1 Verify applicable prerequisites from Section 7 have been completed.

$21.2\}$ TO BE RE-RUN NOTE: DER ECN $w-320-812$

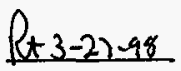

$R+3-27-98$ Ri3-27-98

$k+3-27-98$

R 53.2798 le 3-27.98 l+3.27.94

\subsection{1}

21.2 .2

21.2 .3

$R+3-27-98$

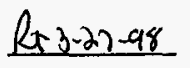

21.2.9

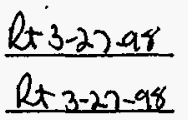

21.2.8

21.2.4

21.2 .5

21.2 .6

21.2.7

\section{9} .154 inches $\mathrm{H}_{2} \mathrm{O}$.

On CP-01, record the current reading from PIC-1361: On IR-1361 in Process BIdg 241-C-91, record the current reading from PIT-1361: .1445 inches $\mathrm{H}_{2} \mathrm{O}$.

In CP-01 in MO-211, disconnect transmitter (PIT-1361) lead wiring from terminals TB-1-6 and TB-1-80:7 ECN $w-320.7 \%$.

Verify that fuse block 4 is lifted (this disables the evacuation hom PAL-1361B).

Veify that fuse block 4 is iffed (this difables the evacualon hom PAL-1301B). Connect transmitter simulator (4-20 mA source) to terminals TB-1-6 and TB-1- 80 ; Apply $8.00 \mathrm{~mA}$, verify response on DAS screen falls within the tolerance of -6.25 \pm 0.05 inches $\mathrm{H}_{2} \mathrm{O}$, and record results from DAS: -6.253 inches $\mathrm{H}_{2} \mathrm{O}$. Verify reading from $\mathrm{PIC}-1361$ is approximately the same as that recorded.

Apply $12.00 \mathrm{~mA}$, verify response on DAS screen falls within the tolerance of -2.5 \pm 0.05 inches $\mathrm{H}_{2} \mathrm{O}$, and record results from DAS: $-25 \mathrm{O}_{2}$ inches $\mathrm{H}_{2} \mathrm{O}$. Verify reading from $\mathrm{PIC}-1361$ is approximately the same as that recorded.

Apply $16.00 \mathrm{~mA}$, verify response on DAS screen falls within the tolerance of 1.25 \pm 0.05 inches $\mathrm{H}_{2} \mathrm{O}$, and record results from DAS: 1.249 inches $\mathrm{H}_{2} \mathrm{O}$. Verify reading from $\mathrm{PIC}-1361$ is approximately the same as that recorded.

21.2.10 Go to the DAS ALARMS screen (F6). Acknowledge all active alarms (F12).

21.2.11 Apply $12 \mathrm{~mA}$, then IJCREASE the input signal until the LOW VACUUM alarm trips. This will cause a sound to play, a message window to appear, and a flashing AMBER annunciator window. Record results from DAS the LOW VACUUM alarm trip point listed in the message window: $=.48$ inches $\mathrm{H}_{2} \mathrm{O}$ (should be $-0.5 / \pm 0.05$ inches $\mathrm{H}_{2} \mathrm{O}$ ). Record results from the transmitter simulator: $14.15 \mathrm{~mA}$.

\section{$k+3-27.98$}

W320DAS.ATP
21.2.12 Click DISMISS on the message window. Acknowledge the alarm. The annunciator window will stop flashing and the alarm sound will stop.

$$
\begin{aligned}
& \text { SEE PNGES } 39 A, B, C \text { FOR }-40 \text { - } \\
& \text { RERUN } B P 7.36-98
\end{aligned}
$$

HNF-1828, Rev.0

Page 45 
21.2.13 Slowly decrease input Until LOW VACUUM alarm clears. Record reset point from DAS: -.703 inches $\mathrm{H}_{2} \mathrm{O}$. Verify that the reset point is no greater than 0.7 \pm 0.05 inches $\mathrm{H}_{2} \mathrm{O}$. Record current reading from the transmitter signulator: $13.92 \mathrm{~mA}$.

$8+3-27-98$

21.2.14 INCREASE the input signal past the LOW VACUUM alarm sefpoint and until the LOW LOW VACUUM alarm trips. This will cause a different found to play, a message window to appear, and a flashing RED annunciat $\phi$ r window. Record results from DAS the LOW LOW VACUUM alarm trip point listed in the message window: -0.01 inches $\mathrm{H}_{2} \mathrm{O}$ (should be $\mathrm{O} \pm 0.05$ inches $\mathrm{H}_{2} \mathrm{O}$ ). Record results from the transmitter simulator: 4,6$) \mathrm{mA}$.

P+ 3-30-98 R $3-30-98$ R+3-30.98 $R+3-30-98$ L+3-30-98

\subsubsection{8} 21.2.19

\author{
21.2.15
}

21.2.16

\subsubsection{7}

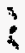
Click DISMISS on the message window. Acknowledge the alarm. The annunciator window will stop flashing and the alagm sound will stop.

Slowly decrease input until the LOW LOW VACUUM alarm clears. Record reset point from DAS: -205 inches $\mathrm{H}_{2} \mathrm{O}$. Verify that the reset point is approximately $-0.2 \pm 0.05$ inches $\mathrm{H}_{2} \mathrm{O}$. Record current reaging from the transmitter simulator: $14.45 \mathrm{~mA}$. On ANN-1361, verify, RESET, and verify that PAL-1361 is STEADY ON. Apply $12 \mathrm{~mA}$, then DECREASE the input signal until the HIGH VACUUM alam trips. This will cause a sound to play, /a message window to appear, and a flashing AMBER annunciator window. Record results from DAS the HIGH VACUUM alarm trip point listed in the message window: $=4.00$ inches $\mathrm{H}_{2} \mathrm{O}$ (should be $-4 \pm 0.05$ inches $\mathrm{H}_{2} \mathrm{O}$ ) Record results from the transmitter simulator: $10.40 \mathrm{~mA}$.

$\operatorname{l+3} 3-30-98$ $R+3-30-91$ R+3-30-98

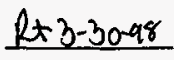

DELETED BY ECN-W320-798 $R+3-27.98$ $(+3-2) 98$

\subsubsection{0}

21.2.21

21.2.22

\subsubsection{3}

On ANN-1361, verify and ackprowledge PAH-1361.
A $w-320-798$

On ANN-1361, verify, RESET, and verify that PAL-1361 is OFF.

Click DISMISS on the message window. Acknowledge the alarm. The annunciator window will stop flashing and the alarm sound will stop.

Slowly increase input until HIGH VACUUM alarm clears. Record reset point from DAS: $-3,299$ inches $\mathrm{H}_{2} \mathrm{O}$. Verify that the reset point is at least $-3.8 \pm 0.05$ inches $\mathrm{H}_{2} \mathrm{O}$. Record curreht reading from the transmitter simulator: $10,62 \mathrm{~mA}$.

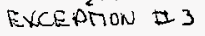

21.2.24-OA-ANA-1361, yerify, RESET, and verify thatPAH-1361 is STEADY ON.

21.2.25 DECREASE the input signal past the HIGH VACUUM alarm setpoint and until the HIGH HIGHVACUUM alarm trips. This will cause a different sound to play, a message window to appear, and a flashing RED annunciator window. Record results from DAS the HIGH HIGH alarm trip point listed in the message window:

-5.80 ihches $\mathrm{H}_{2} \mathrm{O}$ (shouid be $-5.8 \pm 0.05$ inches $\mathrm{H}_{2} \mathrm{O}$ ). Record results from the transmitter simulator: $8.48 \mathrm{~mA}$.

21.2.26 Click DISMISS on the message window. Acknowledge the alarm. The annunciator window will stop flashing and the alarm sound will stop. SEE PAGES 39 A,B,C FOR RERUN GP7-30.78 
21.2.27 Slowly increase input until HIGH HIGH alarm clears. Record reset poift from DAS: $-5,6 \mathrm{O}$ inches $\mathrm{H}_{2} \mathrm{O}$. Verify that the reset point is no less than $-5.6 \pm 0.05$ inches $\mathrm{H}_{2} \mathrm{O}$. Record current reading from the transmitter simulator: $8 \mathrm{2} 22 \mathrm{~mA}$.

$\operatorname{lt}+3-27.98$

$2+3.27 .98$

$R+3.2706 \%$

Rt 4-9-98

$R+4-998$

21.2.28 Disconnect transmitter simulator installed in Step 21.2.5.

21.2.29 Reconnect transmitter lead wiring to terminals disconnected in Step 21.2.4.

21.2.30 Verify reading on DAS is the same as that recorded in Step 21.2.1.

ECN W $320-798 \quad 21.2 .2$

21.2.31 Verify reading on PIC-1361 is the same as that recorded in Step $21-1.2$.

ECNW.320-798 $21.2,3$

21.2.32 Verify reading on PIT-1361 is the same as that recorded in Step 21.1 .3 .

SEE PAGES $39 A, B, C$ FOR RE RUN PP $-30-98$

21.3 BOOSTER PUMP DISCHARGE PRESSURE (PIT-1362) SIMULATION

RT $3-28-98$ 21.3.1 Go to the C-106 STATUS screen. Record the current reading for PI-1362: $=1.5$ psig.

P+3-28 -94 21.3.2 At IE-1362 in 241-C-51, record current reading for PSL/PIT-1362: $=1.2$ psig.

A+3-28-98_ 21.3.3 Deenergize PSLPIT-1362. On rear of PSLPIT-1362, disconnect PE-1362 lead wires and connect

A.3-28.9.4 21.3.4 Energize PSLPIT-1362 and verify PSLPIT-1363 indicates approximately 0 psig.

Rt-3-28_as 21.3.5 Verify response on DAS screen is $0 \pm 1$ psig.

$\operatorname{R+3-25.98}$

21.3.6 On ANN-1363, verify and acknowledge alarm PAL-1362.

DELETED BV EXCEPNOW 44

EUNW320-798 21.3.7-OnCP-01 and ANA-1361, verify atarm XA-1369is in ALERT Condition, then acknowledge.

Lt $3-2894$ 21.3.8 increase source until PSLPIT-1362 indicates 130 psig and reset alarm PAL-1362 and verify that it is in NORMAL condition.

DELETED BY EXLEDTION ITA

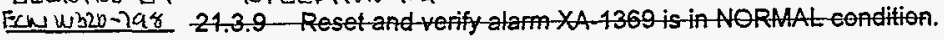

$R+3.2898$ 21.3.10 Verify response on DAS screen is $130 \pm 1$ psig.

RE3-28-q4 21.3.11 Decrease source until PSLJPIT-1362 indicates 120 psig. Verify alarm PAL-1362 is in ALERT condition.

DELETED BN EXCEDTION

ECNW320-798 21.3.12 Verify alarm XA-1369-is in ALERT-condition, then acknowiedge.

Bt $3-24-94$ 21.3.13 Verify response on DAS screen is $120 \pm 1$ psig.

Rt 3-28-98 21.3.14 Increase source until PSLJPIT-1362 indicates 130 psig, Verify and RESET alarm PAL-1362 and verify that it is in NORMAL condition.

DELETED BN ReNum2b-ias $R+3-2898$ R+ 3-28-28 EXUEPTION $\triangle A$

21.3 .15 - Reset and verify alam $\times 4.1369$ is in NORMAL condition.

21.3.16 Verify response on DAS screen is $130 \pm 1$ psig.

21.3.17 Unplug/deenergize PSL/PIT-1362. Disconnect pressure simulator and reconnect PE-1362 lead wires. 
21.3.18 Reenergize and verify PSL/PIT-1362 indicates approximately 0 psig.

*

21.3.19 Verify response on DAS screen is the same as Pl-1362 \pm 1 psig.

\subsection{BOOSTER PUMP DISCHARGE FLOW (FI-13616) SIMULATION}

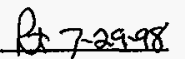

21.4.1

Go to the C-106 STATUS screen. Record the current reading for FI-13616B: $0.29 \mathrm{gpm} ; \mathrm{FIT/EQT-13616}$ (IR-1361): 0.0 gpm, and; Fl-13616A (IE-1362):

$$
\text { ECN-320-798 }
$$

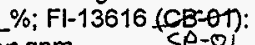

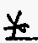

*

米

米

$*$

$*$

斗

*

*

$+5$

21.4 .9

21.4.10

21.4 .8

21.4.3

21.4 .4

21.4 .5

21.4 .6

Apply $12.00 \mathrm{~mA}$. Slowly increase the signal, and verify the measured step size is less than the maximum of $0.5 \mathrm{gpm}$. Record the resolution from DAS: gpm.

In CP-01 in MO-211, disconnect transmitter lead wiring from terminals TB1-69 and TB1-78 at FIT-13616.

Connect transmitter simulator (4-20 mA source) to terminals TB1-69 and TB1-78. Apply $8.00 \mathrm{~mA}$, verify response on DAS screen falls within the tolerance of $125 \pm$ $1 \mathrm{gpm}$, and record results from DAS: gpm.

Apply $16.00 \mathrm{~mA}$, verify response on DAS screen falls within the tolerance of 375 $\pm 1 \mathrm{gpm}$, and record results from DAS: gpm.

Go to the DAS ALARMS screen (F6). Acknowledge all active alarms (F12).

Apply $12 \mathrm{~mA}$, then INCREASE the input signal until the HIGH alarm trips. This will cause a sound to play, a message window to appear, and a flashing AMBER annunciator window. Record results from DAS the HIGH alarm trip point listed in the message window: results from the transmitter simulator: $\mathrm{gpm}$ (should be approximately $425 \mathrm{gpm}$ ). Record

Click DISMISS on the message window. Acknowledge the alarm. The annunciator window will stop flashing and the alarm sound will stop.

Slowly decrease input until HIGH alarm clears. Record reset point from DAS: $\mathrm{gpm}$. Verify that the reset point is no greater than approximately 417 $\mathrm{gpm}$. Record current reading from the transmitter simulator: mA.

21.4.11 INCREASE the input signal past the HIGH alarm setpoint and until the HIGH HIGH alarm trips. This will cause a different sound to play, a message window to appear, and a flashing RED annunciator window. Record results from DAS the HIGH HIGH alarm trip point listed in the message window: be approximately $450 \mathrm{gpm}$ ). Record results from the transmitter simulatór: $\mathrm{mA}$.

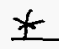



*

W320DAS.ATP
21.4.12

Click DISMISS on the message window. Acknowledge the alarm. The annunciator window will stop fiashing and the alarm sound will stop.

21.4.13 Slowly decrease input until the HIGH HIGH alarm clears. Record reset point from DAS: $\mathrm{gpm}$. Verify that the reset point is no greater than approximately $442 \mathrm{gpm}$. Record current reading from the transmitter simulator: $\mathrm{mA}$.

21.4.14 Apply $12 \mathrm{~mA}$, then DECREASE the input signal until the LOW alarm trips. This will cause a sound to play, a message window to appear, and a flashing AMBER annunciator window. Record results from DAS the LOW alarm trip point listed in * see pollowing Palle for original signoffs ba7-2998 * SEE POLlOWING - 43 - HNF-1828, Rev. 0 Page 47-a

HNF-1827 (QTP/ATP) 


\subsection{BOOSTER PUMP DISCHARGE FLOW (FI-13616) SIMULATION}

Bt $4=9-9 \gamma, 21.4 .1$ Go to the C-106 STATUS screen. Record the current reading for FI-13616B:

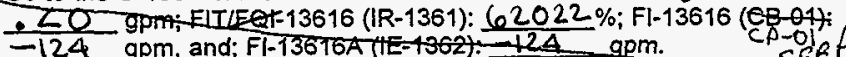

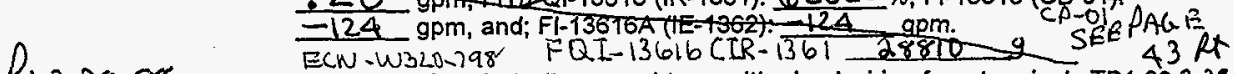

A 3-28-98 21.4.2 in CP-01 in MO-211, disconnect transmitter lead wiring from terminals TB1-69 3-2998 and TB1-78 at FIT-13616.

R+3-25-98

21.4.3 Connect transmitter simulator (4-20 mA source) to terminals TB1-69 and TB1-78.

R+3.24.94. 21.4.4

Apply $8.00 \mathrm{~mA}$, verify response on DAS screen falls within the tolerance of $125 \pm$ $1 \mathrm{gpm}$, and record results from DAS: $125,15 \mathrm{gpm}$.

R+ 3-28.98 21.4 .5

Apply $16.00 \mathrm{~mA}$, verify response on DAS screen falls within the folerance of 375 $\pm 1 \mathrm{gpm}$, and record results from DAS: $32534 \mathrm{gpm}$.

R+ 3.25.98 21.4 .6

Apply $12.00 \mathrm{~mA}$. Slowly increase the signal, and verify the measured step size is less than the maximum of $0.5 \mathrm{gpm}$. Record the resolution from DAS: .4 gpm.

h+3-28-98 21.4.7 Go to the DAS ALARMS screen (FG). Acknowiedge all active alarms (F12).

Rt $3-28-98$ 21.4.8

Apply $12 \mathrm{~mA}$, then INCREASE the input signal until the HIGH alarm trips. This will cause a sound to play, a message window to appear, and a flashing AMBER annunciator window. Record results from DAS the HIGH alarm trip point listed in the message window: $425.0 \mathrm{gpm}$ (should be approximately $425 \mathrm{gpm}$ ). Record results from the transmitter simulator: $17.6 \mathrm{~mA}$.

$\underline{Q+3-28-98}$

21.4 .9

Rt $3-28-98$

21.4.10 Slowly decrease input until HIGH alarm clears. Record reset point from DAS: Al6. $3 \mathrm{gpm}$. Verify that the reset point is no greater than approximately 417 $\mathrm{gpm}$. Record current reading from the transmitter simulator: $12.3 \mathrm{~mA}$.

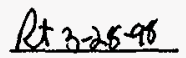

21.4.11

INCREASE the input signal past the HIGH alarm setpoint and until the HIGH HIGH alarm trips. This will cause a different sound to play, a message window to appear, and a flashing RED annunciator window. Record results from DAS the HIGH HIGH alarm trip point listed in the message window: $450.3 \mathrm{gpm}$ (should be approximately $450 \mathrm{gpm}$ ). Record results from the transmitter simulatór. $18.4 \mathrm{~mA}$.

A $3-28-98$ 21.4.12 Click DISMISS on the message window. Acknowledge the alarm. The annunciator window will stop flashing and the alarm sound will stop.

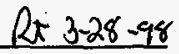

21.4.13

Slowly decrease input until the HIGH HIGH alarm clears. Record reset point from DAS: $44.8 \mathrm{gpm}$. Verify that the reset point is no greater than approximately $442 \mathrm{gpm}$. Record current reading from the transmitter simulator. $18.13 \mathrm{~mA}$.

13 Ean w320-798

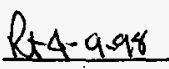

21.4.14 Apply mA, then DECREASE the input signal until the LOW alarm trips. This will cause a sound to play, a message window to appear, and a flashing AMBER annunciator window. Record results from DAS the LOW alarm trip point listed in

$$
-43^{A}
$$


the message window: $225.0 \mathrm{gpm}$ (should be approximately 275 ). Record results from the transmitter simulator: $12.79 \mathrm{~mA}$.

21.4.15 Click DISMISS on the message window. Acknowedge the alarm. The annunciator window will stop flashing and the alarm sound will stop.

Re+3-28.08

21.4.16 Slowly increase input until the LOW alarm clears. Record reset point from DAS: $283.64 \mathrm{gpm}$. Verify that the reset point is at least $283 \mathrm{gpm}$. Record current reading from the transmitter simulator: $13,07 \mathrm{~mA}$.

A 3.28.98 21.4.17 DECREASE the input signal past the LOW alarm setpoint and until the LOW LOW alarm trips. This will cause a different sound to play, a message window to appear, and a flashing RED annunciator window. Record results from DAS the LOW LOW alarm trip point listed in the message window: $249.8 \mathrm{gpm}$. (should be approximately $250 \mathrm{gpm}$ ). Record results from the transmitter simulator. $11.99 \mathrm{~mA}$.

Rt 3-28-94 21.4.18 Click DISMISs on the message window. Acknowledge the alarm. The annunciator window will stop flashing and the alarm sound will stop.

$12+3-2898$

21.4.19 Siowly increase input until LOW LOW alarm clears. Record reset point from DAS: $258.1 \mathrm{gpm}$. Verify that the reset point is at least $258 \mathrm{gpm}$. Record current reading from the transmitter simulator: $12.26 \mathrm{~mA}$.

$k+3-2898$

21.4.20 Disconnect transmitter simulator installed in Step 21.4.3.

$h+3-2898$

21.4.21 Reconnect transmitter lead wiring to terminals disconnected in Step 21.4.2.

$k+4-9.98$

21.4.22 Verify readings on FI-13616B (DAS), FIT/FeI-13616, FI-13616, and FI-13616A are the same as that recorded in Step 21.4.1. FQ1 13616

SIMILARTO

\section{END OF SECTION 21}


g. On Page 44, ADD Section 21.5 as follows:

\subsection{SLURRY BOOSTER PUMP P-1362 VSD FAILURE ALARM}

NOTE: On ANN-1363A and ANN-1363B, it is acceptable to temporary deactivate any alarm that may be in an alarm state, with the exception of alarm XA-1361.

\& $7117 / 98$ 21.5.1 At B1dg $241-C-51$ (EES), on ANN-1363A and ANN-1363B, verify all

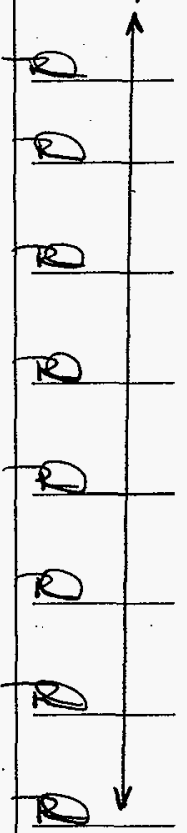

21.5.2 On ANN-1361, verify TANK 241-C-106 BSTR/SBM PUMPS TROUBLE (XA-1369) al arm (window 6-3) is in the NORMAL condition.

21.5.3. At Bldg 241-C-51, in VSD Cabinet, 1ift wires ANN-1363B-7 and ANN-1363B- $(+)$ from terminals 134 and 135 . Install a test switch across teminats 134 and $135 . / P 1>-17-98$

21.5.4 OPEN test switch. On ANN-1363B, verify BSTR PMP VSD FAILURE (XA-1361) alarm (window 7) is FLASHING. Acknowledge and then verify alarm is STEADY ON.

21.5.5 On ANN-1361, verify that TANK 241-C-106 BSTR/SBM PUMPS TROUBLE (XA-1369) alarm (window 6-3) is FLASHING. Acknowledge and then verify alarm is STEADY ON.

21.5.6 CLOSE test switch. On ANN-1363B, reset BSTR PMP VSD FAILURE (XA-136I) alarm (window.7) and then verify alarm is in the NORMAL condition.

21.5.7 On ANN-1361, reset TANK 241-C-106 BSTR/SBM PUMPS TROUBLE (XA-1369) al arm (window 6-3) and then verify alarm is in the NORMAL condition.

21.5.8 Remove test switch from terminals 134 and 135. Reconnect wires ANN-1363B-7 and ANN-1363B- $(t)$ to terminals 134 and 135 respectively.

21.5.9 Verify that any alarms that were temporily deactivated are restored to service. 
h. On Page 44, ADD Section 21.6 as follows:

21.6 SUBMERSIBLE PUMP WINCH $W-1361$ LOWER TRAVEL LIMIT ALARM.

27 7/18/98 21.6.1 On ANN-1361, verify SBM PUMP P-1361 EXTENDED PSN TRAVEL LIMIT

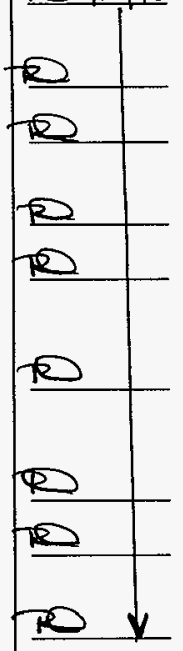
(ZAL-13616) al arm (window 7-2) is in the NORMAL condition.

21.6.2 In CP-01, at terminal block TB-3, open fuse holder FU-9.

21.6.3 At Pump Pit terminal box 3 , terminal block WL, perform zero energy check and then install a test switch across terminals 6 and 8.

21.6.4 In CP-01, at terminal block TB-3, close fuse holder FU-9.

21.6.5 Close test switch. On ANN-1361, verify SBM PUMP P-1361 EXTENDED PSN TRAVEL LIMIT (ZAL-13616) alarm (window 7-2) is FLASHING. Acknowledge and then verify alarm is STEADY ON.

21.6.6 Open test switch. On ANN-1361, reset SBM PUMP P-1361 EXTENDED PSN TRAVEL LIMIT (ZAL-13616) alarm (window 7-2) and then verify alarm is in the NORMAL condition.

21.6.7 In CP-01, at terminal block TB-3, open fuse holder FU-9.

21.6.8 At Pump Pit terminal box 3, terminal block WL, perform zero energy check and then remove test switch from terminals 6 and 8.

21.6.9 In CP-01, at terminal block TB-3, close fuse holder FU-9. 
'22 POWER INTERRUPTION/RECOVERY (UPS SYSTEM PROTECTION)

Tests temporary battery backup power for MO-211 and AY-801A PLC/HMI components. AY-102 HVAC system has emergency diesel generators; these are not tested.

At $3-22.98 \cdot 22.1$ Verify that applicable prerequisites in section 7 have been completed.

Rt $3-27-94$ 22.2 Log in to the WRSS DAS as an Operator. Go to the TREND SELECTION screen. Configure a trend plot containing the tags listed in Data Sheet 22, with a span of 10 minutes.

Rt4.9.98

22.3

DISPLAVED

EuN w320-798

Pt.3-3i-94

22.4 Note the time: 1444 . Remove AC power from the M0-211 UPS by remêving fuse FU-10 from TB3 in IE-1363. Verify that the DAS continues to operate normally. Record the current values for the tags listed in Data Sheet 22.

$R+3-31-94$

Five minutes after the time noted in Step 22.4, retum the MO-211 UPS to AC power by putting the fuse FU-10 back in place. Verify that the DAS continues to operate normally. Record the current values for the tags listed in Data Sheet 22.

R+3-30-98

22.6 Note the time: 1331 . Remove AC power from the AY-801A UPS by removing fuse FU-7 from TB3 in IE-0622. Verify that the DAS continues to operate normally. Record the current values for the tags listed in Data Sheet 22.

Lt 3-30-98

22.7 Five minutes after the time noted in Step 22.6, retum the AY-801A UPS to AC power by putting the fuse FU-7 back in place. Verify that the DAS continues to operate normally. Record the current values for the tags listed in Data Sheet 22.

Lt $49.98 \quad 22.8$ Verify that the PLCICOMMUNICATIONS STATUS page indicates no hardware alarms occurred during the test.

\begin{tabular}{|c|c|c|c|c|c|}
\hline \multicolumn{6}{|c|}{ DATA SHEET 22} \\
\hline \multirow{2}{*}{$\begin{array}{l}\text { CURRENT } \\
\text { VALUES }\end{array}$} & \multicolumn{2}{|c|}{$\begin{array}{l}\text { ENN w320-298 } \\
\end{array}$} & TAGS & $\begin{array}{l}E(N)=320-798 \\
T I 06238\end{array}$ & Ecw ${ }^{320}$ \\
\hline & At=0624 & Al-0623 & FI-0622 & $71-\theta 62 \theta$ & 琶的 -394616 \\
\hline VALUE (22.3) & 21.9 & 99.9 & 0.0 & 64.3 & 0.23 \\
\hline VALUE (22.4) & 22.2 & 99.9 & 226.45 & 64.5 & 0.11 \\
\hline VALUE (22.5) & 22.2 & 99.9 & 687.7 & 64.4 & 0.23 \\
\hline VALUE (22.6) & 71.9 & 99.9 & 0.0 & 64.3 & 0.23 \\
\hline VALUE (22.7) & 72.2 & 99.9 & 0.0 & $64 A$ & 0.23 \\
\hline
\end{tabular}

END OF SECTION 22 
This test simulates a few major communications failures, and tests the DAS response. In all cases, the Operator should be notified by a flashing annunciator and a sound unique to communications errors.

let $3-30.98$

23.1 Verify that all applicable prerequisites from section 7 have been completed.

Rt 3-3094 23.2 Verify that the PLC/COMMUNICATIONS STATUS page indicates no hardware alarms.

$R+3-30-2423.3$ simulate HAR Wailure by tuming power switch to OFF.

L $3-30-9423.4$ Verify that a flashing annunciator symbol appears on the DAS screen and that an alarm sounds.

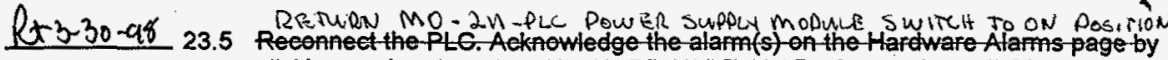
cticking on the alarm text (the-HAROWARE ALARMS-page is-available from the

ECN w-320-7ר1 ALARM SUMMARY OrPLC-and COMMUNHCATIONS-STAFUS pages). The alarm(s) clear(s), and communications return to normal.

RT3-30-98 236 Simult HeOWARE

Simulate HWt failure by tuming power swith

lt $3-30-98$

23.7 SW ITCitES TO ORF.

ECN w-320-171-

Rt $3-30-9823.8$ alarm sounds.

RETURN BOTN AY-SOIA PLC POWER SUPPLY MOARLE SWUTHES TO ON DOSITION Reconnect the PLC. Aeknowledge the-atam(s) on the HARDWARE ALARMS page by clicking on the alam text (the HARDWARE ALARMS-page is-avaitable from the ALARM SUMMMARY-ORPLC and COMMUNHEATIONS-STATUS-pages). The alarm(s) clear(s), and communications return to normal.

\section{END OF SECTION 23}


Upon completion of the lesting steps in each Section, initial and date in the space provided.

\begin{tabular}{|c|c|c|c|}
\hline \multicolumn{4}{|c|}{ Test Completion HNF-1827 (W320, DAS QTPIATP) } \\
\hline & PERFORM & INITIAL & DATE \\
\hline 7 & $\begin{array}{l}\text { Prerequisites, Equipment/instruments, } \\
\text { Definitions, Glossary and Annunciators }\end{array}$ & Rt & 4.9 .98 \\
\hline 8 & HMI Screen Navigation and Function Keys & Bt & $4.9-94$ \\
\hline 9 & HMI Screen Data Display & Pt & 44,98 \\
\hline 10 & Citect Intemal Calculations & Rt & $4-9.98$ \\
\hline 11 & Historical Trending & Bt & $4-9-98$ \\
\hline 12 & HMl Security Functions & R & $4-9-98$ \\
\hline 13 & Alarm Setpoints & Dt & $4-q-q 4$ \\
\hline 14 & System Interfaces & Rt & $\Delta .9-94$ \\
\hline 15 & Mass Flow Transmitter & Rt & $4-9.98$ \\
\hline 16 & ENRAF Density Meter Data File 1/O & Or & $4-9-98$ \\
\hline 17 & Tank AY-102 Ventilation Data File $1 / O$ & R & $4-9-98$ \\
\hline 18 & AY-102 Tank Temperatures & $l_{t}$ & A9998 \\
\hline 19 & $\begin{array}{l}\text { AY-Farm MIT (Type K Thermocouple input } \\
\text { Modules) }\end{array}$ & $R$ & $4-9 \sqrt[9.8]{ }$ \\
\hline 20 & AY Farm Process inputs $(4-20 \mathrm{~mA})$ & Br & $4-9$ as \\
\hline 21 & C-Farm, Process inputs $(4-20 \mathrm{~mA})$ & $B t$ & $4-9.94$ \\
\hline 22 & Power Interruption/Recovery & Dt & $4-9-98$ \\
\hline 23 & Cornm Device Failure Alarms & Rt & $4-998$ \\
\hline
\end{tabular}




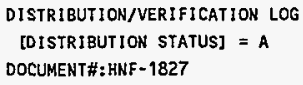

INITIAL

REV DIST, DATE PROJECT\#

PROJECT MITLE

$\mid \begin{aligned} & \text { OISTRIBUtion } \\ & \text { SET\# }\end{aligned}$

$03 / 12 / 98 \quad w-320$

W-320 EQUIPMENT REMOVAL SYSTEM

W-320 EQUIPMENT REMOVAL SYSTEM
|CE-9 K LESSER

I acknowledge 1 have received the documents (set\#) highlighted above. 


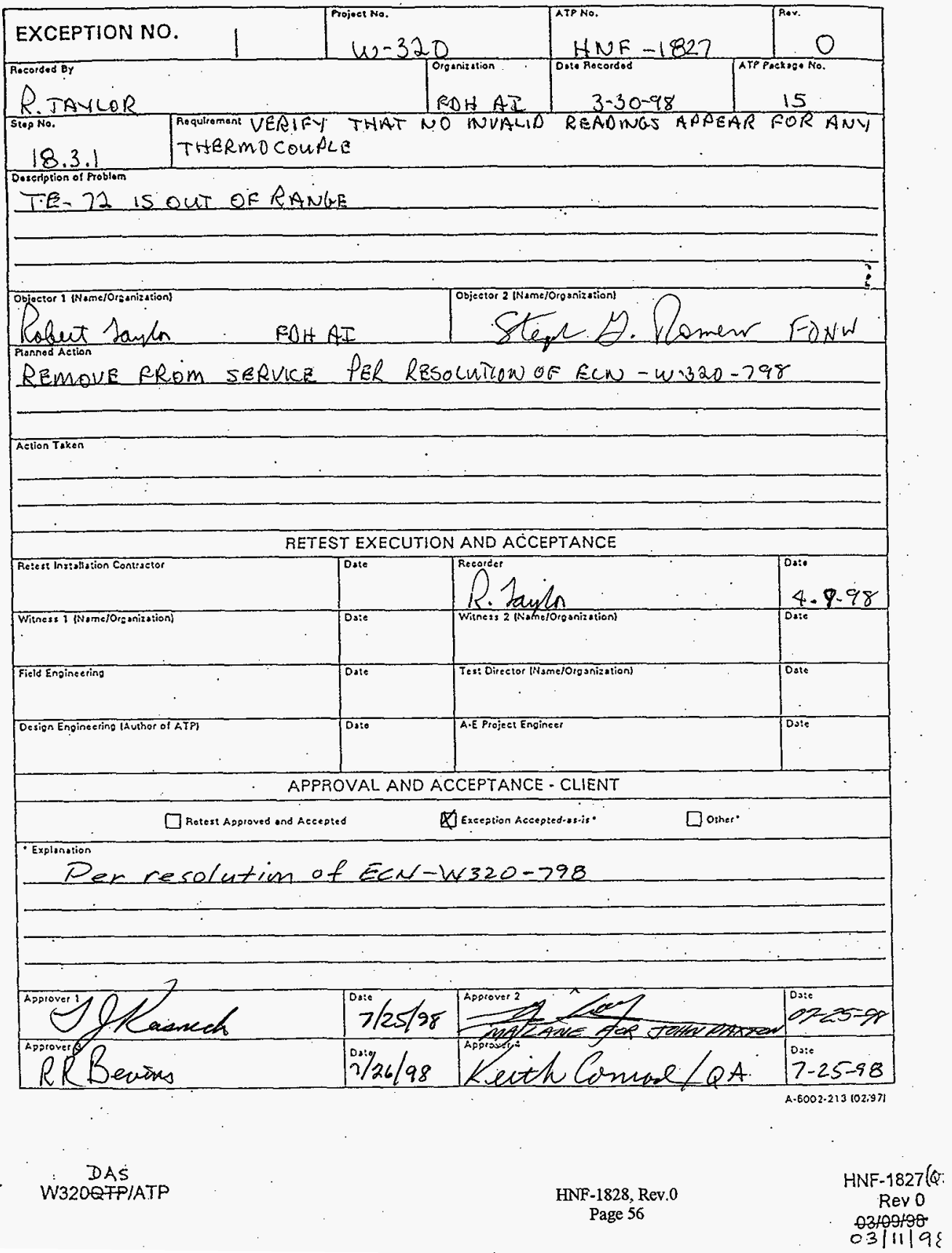




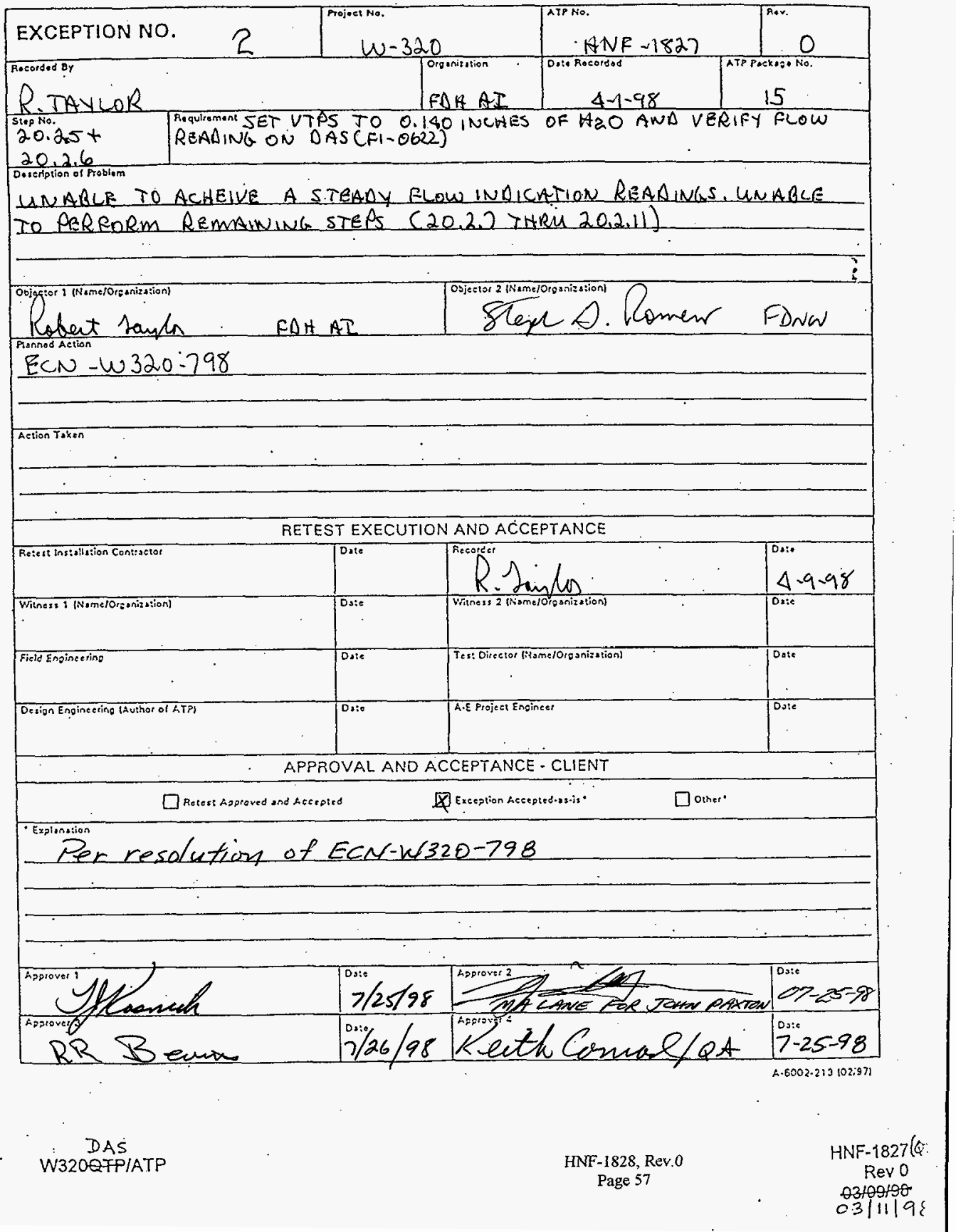




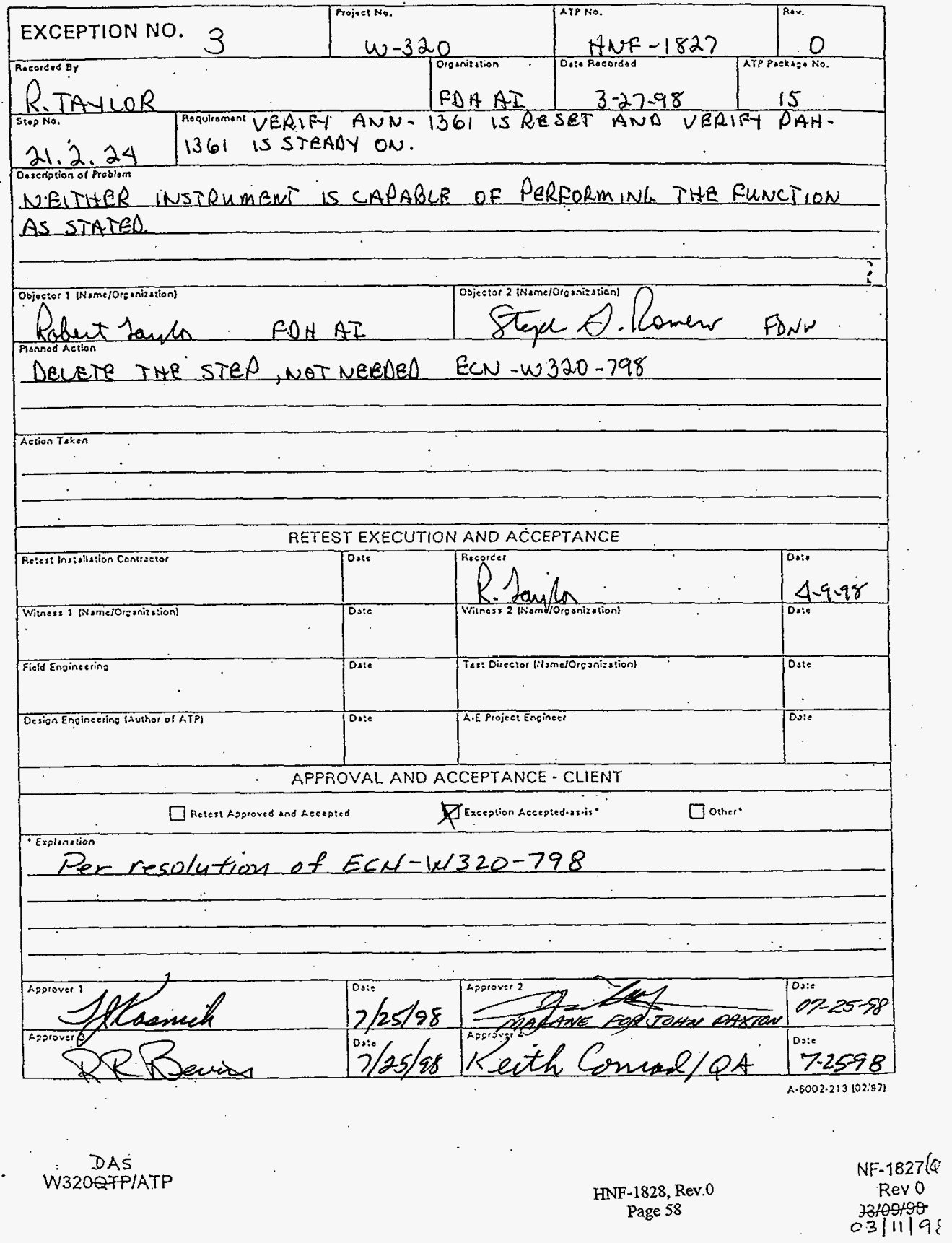




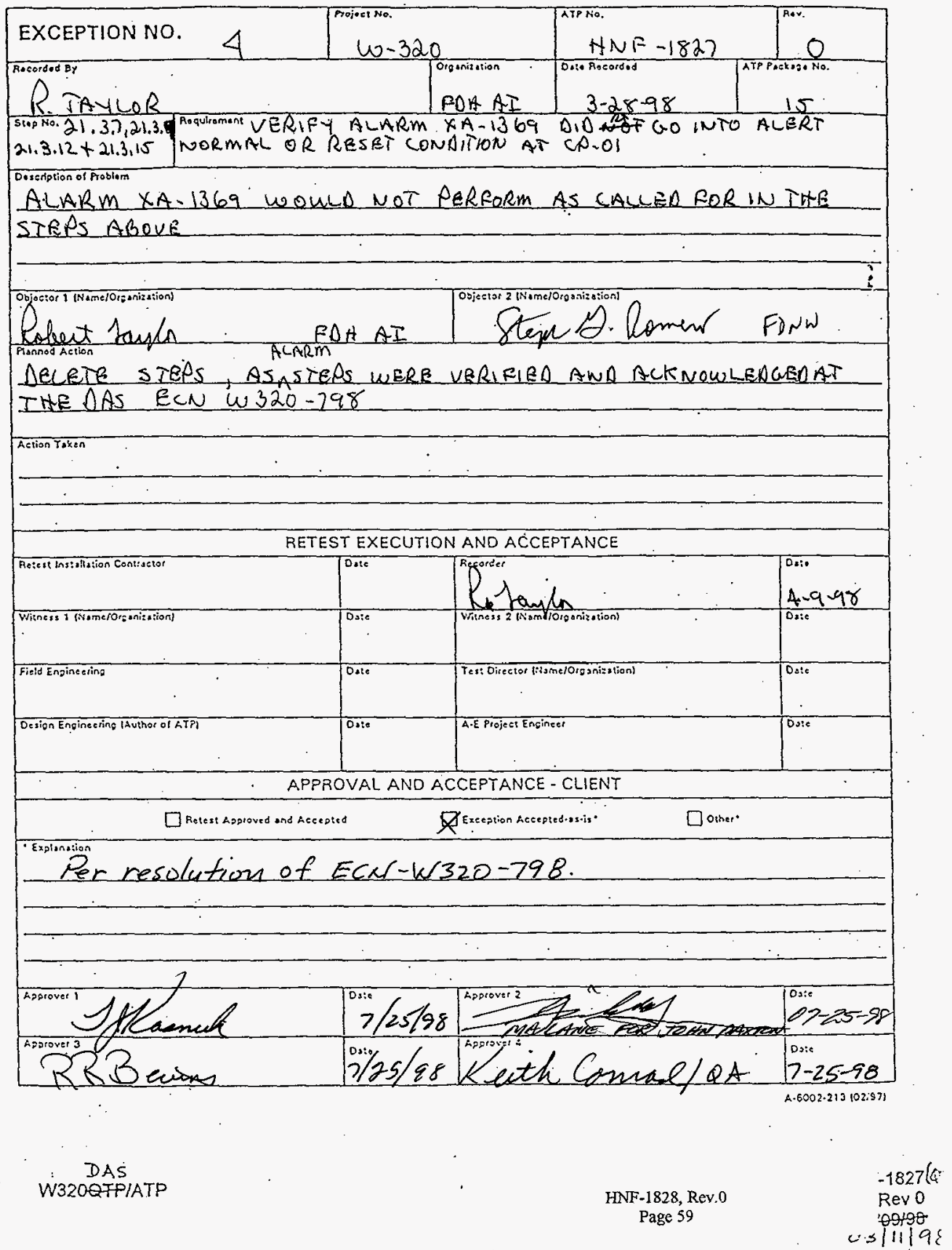




\section{PaG⿱ 2 of Exception}

ENGINEERING CHANGE NOTICE CONTINUATION SHEET

Page 6 of 10

ECN $W-320-812$

Date $6 / 18 / 98$

f. On Page 40, delete and replace Section 21.2 as follows: [Affects ECN W-320-798]

\subsection{TANK 241-C-106 PRESSURE (PIT-1361) SIMULATION}

NOTE: PIT-1361 and PIC-1361 have been tested in HNF-SD-W320-ATP-012 in accordance with Step 16.3. Acknowledge any alarms generated during the steps in this section.

Rt $728-98$ 21.2.1 Go to the $\mathrm{C}-106$ STATUS screen on DAS. Record current reading for PI-1361: .026 inches $\mathrm{H}_{2} \mathrm{O}$.

Rt7-2898 21.2.2 On CP-01, Record the current reading from PIC-1361:

. $\mathrm{O}$ inches $\mathrm{H}_{2} \mathrm{O}$.

Qt 7.2898 21.2.3 ON IR-1361 in Process B1dg 241-C-91, Record the current reading from PIT-1361: $\quad .1093$ inches $\mathrm{H}_{2} \mathrm{O}$.

EXC $\$ 5$ 21.2.4 Verify readings obtained in above steps are al1 within $+/-0.1$ inches $\mathrm{H}_{2} \mathrm{O}$ of each other.

NA $A^{\text {Pt } 7-2898} 21.2 .5$ In CP-OI, disconnect transmitter (PIT-1361) lead wiring from termina $1 \mathrm{~s}$ TB-1-6 and TB-1-7.

21.2.6 In CP-01, verify that TB-3 fuse block 4 is LIFTED/OPEN (this disables the evacuation horn PAL-1361B).

21.2.7 In CP-01, connect transmitter simulator (4-20 Ma source) to terminals TB-1-6 and TB-1-7.

21.2.8 Apply 8.00 Ma, verify response on DAS screen is -6.25 inches $\mathrm{H}_{2} \mathrm{O}$ $\left(-6.20\right.$ to -6.30 inches $\left.\mathrm{H}_{2} \mathrm{O}\right)$. Record results from DAS:

inches $\mathrm{H}_{2} \mathrm{O}$. Verify response on PIC-1361 is -6.1 to -6.4 inches $\mathrm{H}_{2} \mathrm{O}$ ) Record results from PIC-1361: inches $\mathrm{H}_{2} \mathrm{O}$.

21.2.9 Apply $12.00 \mathrm{Ma}$, verify response on DAS screen is -2.50 inches $\mathrm{H}_{2} \mathrm{O}$ $\left(-2.45\right.$ to -2.55 inches $\left.\mathrm{H}_{2} \mathrm{O}\right)$. Record results from DAS:

inches $\mathrm{H}_{2} \mathrm{O}$. Verify response on PIC-1361 is -2.4 to -2.6 inches $\mathrm{H}_{2} \mathrm{O}$ ) Record results from PIC-1361: inches $\mathrm{H}_{2} \mathrm{O}$.

21.2.10 Apply 16.00 Ma, verify response on DAS screen is 1.25 inches $\mathrm{H}_{2} 0$ ( 1.20 to 1.30 inches $\mathrm{H}_{2} \mathrm{O}$ ). Record results from DAS:

inches $\mathrm{H}_{2} \mathrm{O}$. Verify response on $\mathrm{PIC}-1361$ is 1.1 to 1.4 inches $\mathrm{H}_{2} \mathrm{O}$ ) Record results from PIC-1361: inches $\mathrm{H}_{2} \mathrm{O}$.

21.2.11 Go to DAS ALARMS screen (F6). Acknowledge all active alarms (F12).

NA 21.2.12 Apply $12 \mathrm{Ma}$, then INCREASE input signal until the LOW VACUUM/LOSS OF VACUUM alarms trip on DAS, PIC-1361 and ANN-1361 (window 1-2). This will cause a sound to play, a message window to appear, and a flashing AMBER annunciator window in DAS. 


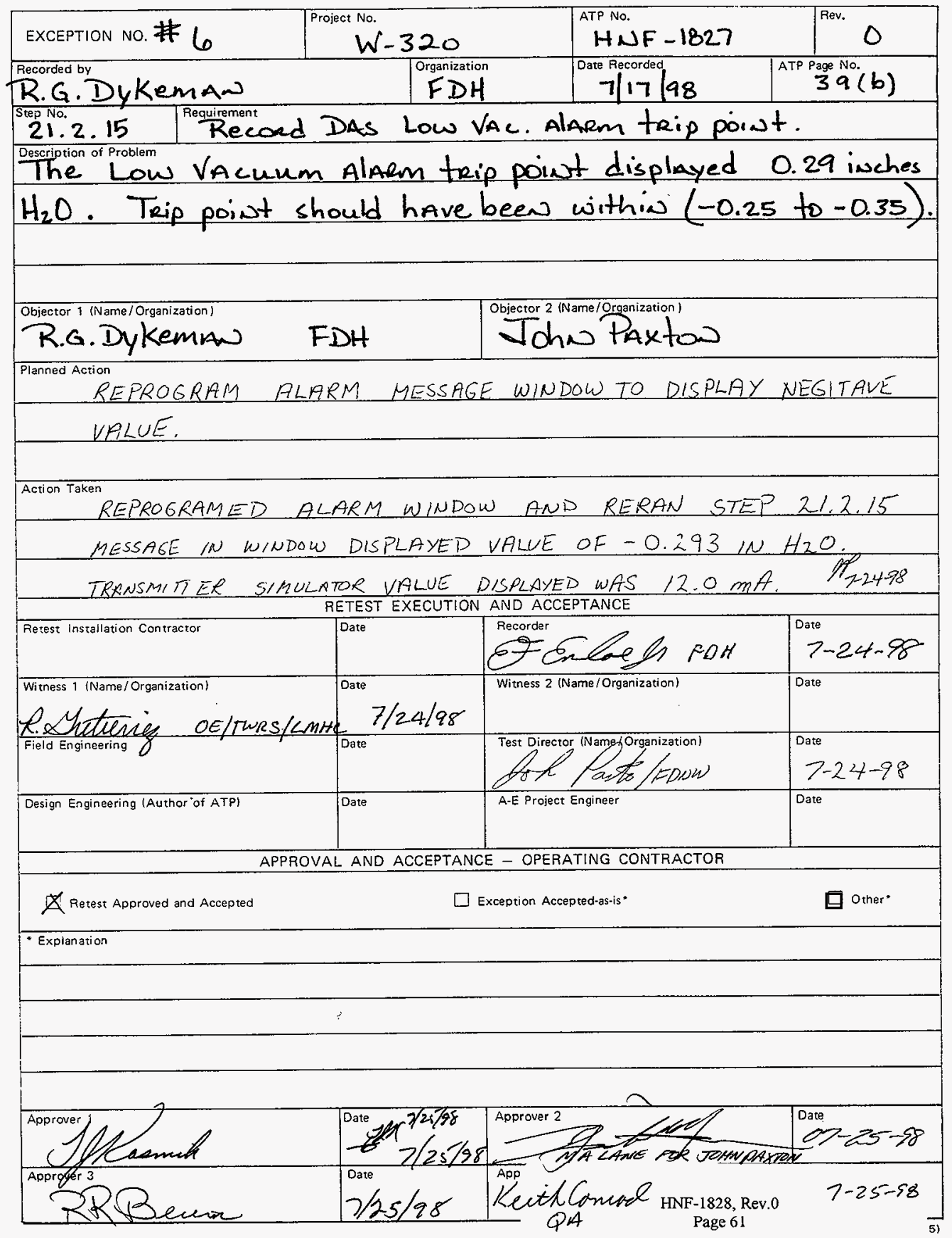




\begin{tabular}{|c|c|c|c|c|c|}
\hline \multicolumn{6}{|c|}{ DISTRIBUTION SHEET } \\
\hline \multirow{2}{*}{$\begin{array}{l}\text { To } \\
\text { Distribution }\end{array}$} & \multirow{2}{*}{$\begin{array}{l}\text { From } \\
\text { JW Bailey }\end{array}$} & & & \multicolumn{2}{|c|}{ Page 1 of 1} \\
\hline & & & & \multicolumn{2}{|c|}{ Date 30 July 1998} \\
\hline \multicolumn{4}{|l|}{ Project Title/Work Order } & \multicolumn{2}{|c|}{ EDT No. 622273} \\
\hline \multicolumn{4}{|c|}{$\begin{array}{l}\text { HNF-1828, Rev. 0, Waste Retrieval Sluicing System, Data } \\
\text { Acquisition System, Acceptance Test Report }\end{array}$} & \multicolumn{2}{|c|}{ ECN No. $n / a$} \\
\hline Name & MSIN & $\begin{array}{c}\text { Text } \\
\text { With All } \\
\text { Attach. }\end{array}$ & Text Only & $\begin{array}{l}\text { Attach./ } \\
\text { Appendix } \\
\text { Only }\end{array}$ & $\begin{array}{l}\text { EDT/ECN } \\
\text { Only }\end{array}$ \\
\hline $\begin{array}{l}\text { DG Baide } \\
\text { JW Bailey } \\
\text { JR Bellomy } \\
\text { RR Bevins } \\
\text { KC Conrad } \\
\text { JM Jones } \\
\text { JW Lentsch } \\
\text { J Paxton } \\
\text { SU Zaman } \\
W-320 \text { Project Files }\end{array}$ & $\begin{array}{l}\text { S5-05 } \\
\text { S2-48 } \\
\text { S2-48 } \\
\text { S2-48 } \\
\text { S2-48 } \\
\text { S5-13 } \\
\text { S2-48 } \\
\text { S2-47 } \\
\text { S5-12 } \\
\text { R1-29 }\end{array}$ & & & & \\
\hline
\end{tabular}

